\title{
Real-Time Characterization of Crystal Shape and Size Distribution Based on Moving Window and 3D Imaging in a Stirred Tank
}

\author{
Rui Zhang1, Xuezhong Wang1,2*, Yang Zhang1* ${ }^{*}$ Tao Liu ${ }^{3}$ \\ ${ }^{1}$ School of Chemistry and Chemical Engineering, South China University of Technology, Guangzhou, China \\ ${ }^{2}$ Centre for Pharmaceutical and Crystallization Process Systems Engineering, School of Chemical Engineering, Beijing Institute of \\ Petrochemical Technology, Beijing, China \\ ${ }^{3}$ Institute of Advanced Control Technology, Dalian University of Technology, Dalian, China \\ Email: *wangxuezhong@bipt.edu.cn, ${ }^{*}$ ceyzhang@scut.edu.cn
}

How to cite this paper: Zhang, R., Wang, X.Z., Zhang, Y. and Liu, T. (2019) Real-Time Characterization of Crystal Shape and Size Distribution Based on Moving Window and 3D Imaging in a Stirred Tank. Journal of Crystallization Process and Technology, 9, 13-38.

https://doi.org/10.4236/jcpt.2019.92002

Received: March 28, 2019

Accepted: April 23, 2019

Published: April 26, 2019

Copyright $\odot 2019$ by author(s) and Scientific Research Publishing Inc. This work is licensed under the Creative Commons Attribution International License (CC BY 4.0).

http://creativecommons.org/licenses/by/4.0/

(c) (i) Open Access

\begin{abstract}
Crystal shape distribution, i.e. the multidimensional size distribution of crystals, is of great importance to their down-stream processing such as in filtration as well as to the end-use properties including the dissolution rate and bioavailability for crystalline pharmaceuticals. Engineering crystal shape and shape distribution requires knowledge about the growth behavior of different crystal facets under varied operational conditions e.g. supersaturations. Measurement of the facet growth rates and growth kinetics of static crystals in a crystallizer without stirring has been reported previously. Here attention is given to study on real-time characterization of the 3D facet growth behavior of crystals in a stirred tank where crystals are constantly moving and rotating. The measurement technique is stereo imaging and the crystal shape reconstruction is based on a stereo imaging camera model. By reference to a case study on potash alum crystallization, it is demonstrated that the crystal size and shape distributions (CSSD) of moving and rotating potash alum crystals in the solution can be reconstructed. The moving window approach was used to correlate $3 \mathrm{D}$ face growth kinetics with supersaturation (in the range $0.04-0.12)$ given by an ATR FTIR probe. It revealed that $\{100\}$ is the fastest growing face, leading to a rapid reduction of its area, while the $\{111\}$ face has the slowest growth rate, reflected in its area continuously getting larger.
\end{abstract}

\section{Keywords}

Stereo Imaging Camera Model, Crystal Size and Shape Distribution, 3D Reconstruction, Potash Alum, Facet Growth Kinetics 


\section{Introduction}

On-line microscopic imaging and image analysis for real-time characterization of crystallization processes has attracted much attention in recent years. While much of the published work was based on study on 2D imaging technique, 3D imaging seems to hold more promise. This is because crystal size and shape distributions (CSSD) should be the size distributions over more than one size dimension.

In a comparison of $2 \mathrm{D}$ and $3 \mathrm{D}$ imaging for crystallization characterization of needle-shaped crystals [1], it was found that 2D imaging based technique could underestimate the crystal length by $2 / 3$, while the $3 \mathrm{D}$ imaging approach estimated the length much more accurately. A novel device was designed for direct measurement of face specific growth kinetics of growing crystals based on 3D online imaging technique through fixing a seed onto the pipeline in a flowcell rather than a stirred tank [2]. Ma et al. [3] proposed the triangulation method to reconstruct three different crystals $3 \mathrm{D}$-shape in a reactor. However, the facet growth kinetics was not reported. Zhang et al. [1] also applied stereo vision imaging to measuring the size and shape of needle-like crystals in stirred tank crystallizer. The triangulation algorithm was also employed to reconstruct the $3 \mathrm{D}$ shape. It is noticed that the triangulation algorithm has successfully reconstructed the 3D shape for needle, plate and rod like crystals, but it is difficult for crystals with more complicated structures. The main limitation of the triangulation of $3 \mathrm{D}$ reconstruction algorithm is that it relies on accurate identification of all the corners of each crystal on the 2D images, which proved to be challenging. For this reason, a new reconstruction method named stereo imaging camera model was presented and applied to static crystals growing in crystallizer without a stirrer to obtain a crystal's growth kinetics [4]. In this case, the rotation and motion of crystals were not considered, which may not truly reflect the crystal growth. In this current study, facet growth kinetics of potash alum crystals was derived in a stirred tank crystallizer using stereo imaging camera model. Compared to the previous work mentioned above, the current work has made progress in two aspects: 1) 3D facet growth kinetics of moving and rotating crystals rather than static crystals was measured in a stirred tank; 2) A more effective $3 \mathrm{D}$ reconstruction method, stereo imaging camera model, incorporated with a moving window approach was used to reconstruct the CSSD.

Although the above mentioned work [1] [2] [3] [4] is most relevant to the current paper, other techniques for on-line crystal shape measurement will also be briefly reviewed here. Since there are many papers on crystal shape measurement using 2D imaging, and they are less relevant to the current work focusing on 3D, and also because they have been reviewed in some recent papers [4] [5] [6] [7], here the review will be restricted to those methods that characterize crystal 3D shape.

Li et al. [8] proposed a method called camera model to obtain 3D crystal shape information using on-line captured 2D images taken from a crystallizer, 
but they used only one camera. Borchert et al. [9] developed a method to reconstruct the $3 \mathrm{D}$ crystal shape by comparing Fourier descriptors of the $2 \mathrm{D}$ crystal projections in pre-computed database with the Fourier descriptors of on-line measured 2D images. It is noted that the images were still obtained using a single camera rather than two or more cameras in the above mentioned work. Wang et al. [6] proposed to use two or more synchronized cameras to firstly acquire two or three $2 \mathrm{D}$ images of the same moving crystal from different directions and then reconstruct its $3 \mathrm{D}$ shape from the $2 \mathrm{D}$ images using a reconstruction algorithm. A clever method for measuring $3 \mathrm{D}$ crystal shape through flow cell using a single camera but two mirrors from vertical directions was shown by Mazzotti and co-workers [10] [11]. However, in their later work, they turned to two cameras rather than a single camera plus mirrors [12]. More recently, they developed an optimization method to obtain crystal shape from stereoscopic images in a hot-stage reactor [13]. It needs to point out that in their work the crystals were also static. Huo et al. developed imaging analysis for online identification crystal morphology [14] and detection of particle agglomeration [15] rather than obtaining growth kinetic information based on 3D imaging system. Kovačevic et al. [16] reported a new algorithm for obtaining 3D crystal shape from microcomputed tomography [17]. More recently, they further extended this method for asymmetrical crystals and applied it for studying the disorientation angle distribution (DAD) of potash alum crystals, and could measure the DAD using 3D imaging and the proposed image processing routines [18]. Although this method opens a new idea for estimation full particle size and shape distributions and exploration particle aggregation mechanism, it is still limited to dry particle samples rather than real-time measurement of crystals growing in a solution. Confocal microscopy is able to provide $3 \mathrm{D}$ shape information of specimen through obtaining tomographic images of samples [19], and an image-analysis program was used to measure morphology and identify polymorphs of 3D crystals [20], but the method is slow, takes from half hour to one hour for a single particle and not suitable for on-line monitoring. Computed tomography (CT), referred to as $\mathrm{X}$-ray tomography, which can reconstruct the full 3D structure of a particle through a series of 2D X-ray images [21]. This technique has been applied in extracting $3 \mathrm{D}$ geometric information as well as measuring particle size distribution in different areas [22] [23] [24] [25]. In addition, three-dimensional electron tomography (3D-TEM) is also a method for obtaining the particle $3 \mathrm{D}$ shape [26]. However, CT and 3D-TEM are not suitable for on-line monitoring of crystallization processes.

On the basis the previous proof of concept study on stereo imaging camera model for monitoring static crystals growing in a crystallizer without stirring [4], the current investigation focuses the attention on characterization of $3 \mathrm{D}$ size and shape distribution of potash alum crystals growing in a stirred tank crystallizer where crystals constantly move and rotate. In the following sections, experiments and the methodology of crystal 3-D shape reconstruction are briefly de- 
scribed. Then the facet growth kinetics of potash alum crystals is discussed. Conclusions will be made in the final section.

\section{Crystallization Experiment}

A 1.5 L reactor (Figure 1) was purposely designed to have a silica imaging window to apply the imaging instrument and to minimize convexity effect on images. In Figure 1, the area is labeled "image window". A Julabo FP51-HE thermostatic bath was used to control the temperature by manipulating the water circulation. The temperature was measured using a platinum resistance thermometer (PT100). Solution concentration was measured using an attenuated total reflectance-Fourier transform infrared probe (ATR-FTIR). Potash alum, $\mathrm{KAl}\left(\mathrm{SO}_{4}\right)_{2} \cdot 12 \mathrm{H}_{2} \mathrm{O}$, was chosen as the model chemical. It has four molecules in the cubic unit cell with a space group of $P a \overline{3}$ and cell parameters of $\mathrm{a}=\mathrm{b}=\mathrm{c}=$ $12.517 \AA$ and $\alpha=\beta=\gamma=90^{\circ}$. As shown in Figure 2, the crystal morphology is dominated by the large octahedron face $\{111\}$ and two essential but considerably

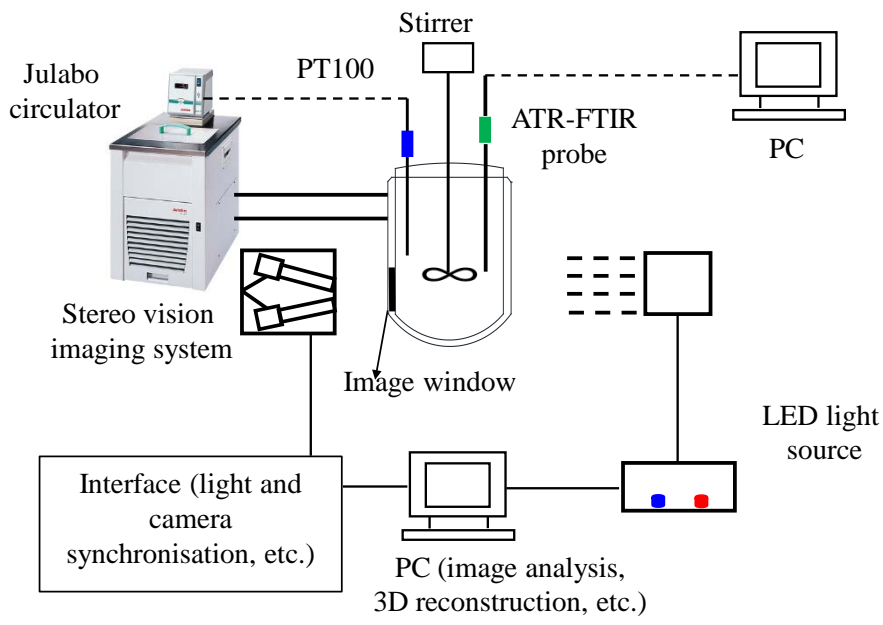

Figure 1. Schematic of the experimental set-up equipped with the stereovision imaging system the "Image window" area was purposely designed to minimize convexity effect.

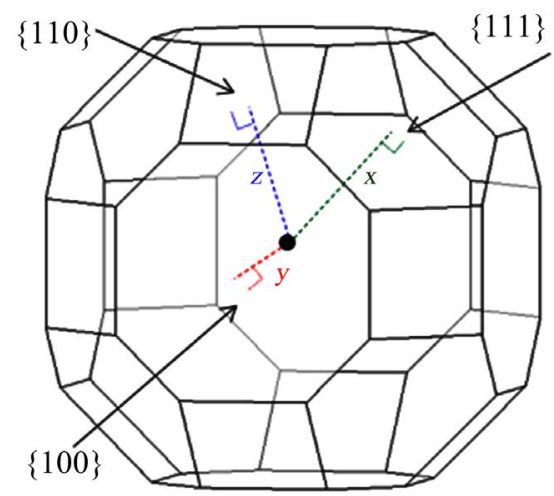

Figure 2. Morphology of potash alum crystal and the three size characteristic parameters $(\mathrm{x}, \mathrm{y}, \mathrm{z})$ for independent crystal faces. 
smaller faces, the cubic face $\{100\}$, and the rhomb-dodecahedron face $\{110\}$ [27] [28] [29] [30]. Three minor faces, $\{221\},\{112\}$ and $\{012\}$, that exist only at early stages during crystallization and disappear quickly, hence, have not been frequently observed. These three primary growth forms are manifested in the external morphology through the multiplicities associated with the cubic symmetry which yields a total of 26 crystal growth surfaces, i.e., eight $\{111\}$, six $\{100\}$ and twelve $\{110\}$ faces as three feature faces. In Figure $2, \mathrm{x}, \mathrm{y}$ and $\mathrm{z}$ stand for the normal distances from geometric center to three feature faces, respectively. The solubility of potash alum crystals can be found in literatures [31] [32].

The on-line imaging system depicted in Figure 1 consists of two IDS CCD cameras (camera 1 and camera 2 as shown in the figure) and two 2x optic lenses. The camera fitted with Sony Imaging sensor can carry out image acquisition with a pixel resolution of $1280 \times 1024$ under a maximum frequency of up to 15 images per second. Two LED light sources were used to provide illumination for cameras. A PC running StereovisionNI software developed by PharmaVision Ltd was used for acquisition, storage and management of the images. The relative measurement error is less than $2 \%$.

Saturated solution (at $31^{\circ} \mathrm{C}$ saturation temperature) was prepared with $170 \mathrm{~g}$ of potash alum and $1 \mathrm{~L}$ of fresh distilled water. The solution was heated quickly to $40^{\circ} \mathrm{C}$ and held at the temperature for an hour until the solids were fully dissolved. The solution was then cooled down to $30^{\circ} \mathrm{C}$ at a relatively fast cooling rate of $1^{\circ} \mathrm{C} / \mathrm{min}$ and maintained at $30^{\circ} \mathrm{C}$ for half hour. After that, the solution was cooled down to $27^{\circ} \mathrm{C}$ at a slow cooling rate of $0.1^{\circ} \mathrm{C} / \mathrm{min}$. The growth of potash alum crystals happened with the decrease of the solute temperature and concentration during the cooling crystallization. For the estimation of crystal shape, the temperature range used was from $30^{\circ} \mathrm{C}$ to $27^{\circ} \mathrm{C}$ and the corresponding relative supersaturation range was from 0.04 to 0.12 .

\section{ATR FTIR Calibration Experiments and Models}

The ATR-FTIR calibration experiments were carried out to collect data for predictive model development. The data contains 30 spectra, corresponding to solutions at temperatures of $10^{\circ} \mathrm{C}, 20^{\circ} \mathrm{C}, 30^{\circ} \mathrm{C}, 40^{\circ} \mathrm{C}$ and $50^{\circ} \mathrm{C}$, and concentration range from 2 to $24 \mathrm{~g} / 100 \mathrm{~g}$ water. The peaks at wavenumbers of $1100 \mathrm{~cm}^{-1}$ and $1640 \mathrm{~cm}^{-1}$ are associated with potash alum sulphate $\left(\mathrm{SO}_{4}^{2-}\right)$ and the $\mathrm{H}-\mathrm{O}-\mathrm{H}$ in water.

Partial least square regression (PLS) [33] [34] [35] was used to develop the concentration predictive model. The calibration data comprises the input variables, i.e. the wave numbers in the range between $800 \mathrm{~cm}^{-1}$ to $1800 \mathrm{~cm}^{-1}$ at 4 $\mathrm{cm}^{-1}$ interval (The IR spectra peak of potash alum is known to be at the wave numbers of $1100 \mathrm{~cm}^{-1}$ and $1640 \mathrm{~cm}^{-1}$ ) and temperature, and the output variable i.e., the solution concentration. Although it was found the influence of temperature on spectra absorbance is not as obvious as solution concentration, temperature was still used as an input variable. The data was randomly divided 
into two sets, the training dataset (18 spectra) for calibration model development and the test dataset (12 spectra) for model verification, which was same as Table 1 in literature 4 as cells and cells with the letter "s", respectively. The R-square values $\left(\mathrm{R}^{2}\right)$ and root mean square of prediction (RMSEP) for the training data and test data are $\mathrm{R}^{2}=0.99997, \mathrm{RMSEP}=0.0021 \mathrm{~g} / \mathrm{g}$ water and $\mathrm{R}^{2}=0.99995$, $\mathrm{RMSEP}=0.0025 \mathrm{~g} / \mathrm{g}$ water using PLS model, respectively.

\section{Crystal 3D Shape Reconstruction}

The stereo imaging camera model described in the paper [4] was use here to reconstruct the 3D shape and estimate the multidimensional sizes of a crystal. The approach for 3D crystal shape reconstruction firstly rotates a digitalized crystal in the three-dimensional space and varies the dimensional sizes in all face directions. At each size and orientation, 2D projections of the crystal, according to the angles of the $2 \mathrm{D}$ cameras, are recorded. The contour information of $2 \mathrm{D}$ images is processed to calculate Fourier descriptors and radius-based signature that are stored in a database. Then when the stereo imaging instrument mounted on a crystallizer captures $2 \mathrm{D}$ images, they are segmented to obtain the contour information and further processes are applied for obtaining their Fourier descriptors and radius-based information. The calculated Fourier descriptors and radius-based signature are used to find the best matching in the database. The corresponding $3 \mathrm{D}$ crystal shape is thus found.

\subsection{The Database}

Since the detailed method of the stereo imaging camera model was previously introduced [4], inhere it will not be repeated. Accurate estimation of the 3D shape and multidimensional sizes of a crystal in a stirred tank mainly depends on two factors: the quality of the captured images, as well as the database containing the Fourier descriptors (FDs) and radii-based information of 2D projections from two different angles of a digital crystal that undergoes rotation in the three-dimensional space and variation in the dimensional sizes of all face directions. For the second factor, the discretization step sizes of the variation of orientation angles and crystal sizes during the generation of the database are important. Smaller discretization step size means higher matching accuracy, but at the expense of larger database and longer CPU time.

The range of crystal size in this work was set from $10 \mu \mathrm{m}$ to $200 \mu \mathrm{m}$ and the step length for variation in each of the three normal distances was set as $5 \mu \mathrm{m}$. Meanwhile, the range and step length of rotation angle were the same as database in the previous paper [4], i.e., $\delta$ and $\varphi$ varied between 0 and $2 \pi, \theta$ was from 0 to $\pi$, whilst the step length was $10^{\circ}$.

An assumption was made that the potash alum crystals always keep 26 faces, despite the fact that it is possible according to Wan et al. [36] that during the growth of a crystal one or two of the three faces $\{111\},\{100\}$ and $\{110\}$ might disappear, resulting seven possible morphological forms. The additional con- 
straint was added that limits the area of a feature face never reaching zero when calculating the area using the equations described in the previous paper [28].

In total, 4334 combinations of three characteristic parameters $(\mathrm{x}, \mathrm{y}, \mathrm{z})$ using the selected size range and step size for the database. The database was generated based on the following settings: $\mathrm{n}_{\mathrm{x}, \mathrm{y}, \mathrm{z}}=4334, \mathrm{n}_{\delta, \varphi, \theta}=23,328$, and $\mathrm{K}=128$, where $\mathrm{n}$ is the number of selected size, $\mathrm{x}, \mathrm{y}, \mathrm{z}$ are the normal distances of three individual faces, and $\delta, \varphi, \theta$ are the Euler angles.

\subsection{Shape Estimation Principle}

For dynamic crystals, though the reconstruction of crystal shape is more challenging, the estimation principle is essentially the same as for static crystals. In our previous work [4], 3D shape of a single static crystal was reconstructed using stereo imaging camera model based on stereo imaging system. Suppose that the crystals in a stirred tank crystallizer (Image A) and a static crystal (Image B) were photographed using the same camera, respectively. There are $2 \mathrm{D}$ projections of several crystals during rotation in the space on Image A, while only a 2D projection on Image B. Actually, these projections on Image A can be considered as the combination of the projection on Image B at different angles. Therefore, estimation of $3 \mathrm{D}$ shape of crystals in stirred tank reactor will become $3 \mathrm{D}$ reconstruction of a series of single crystal. Furthermore, the probability of the same projection (size and shape) crystal generated at different angles is very small in stirred reactor. It is assumed that a potassium crystal rotates randomly at a slow enough speed, the $2 \mathrm{D}$ projections of crystal may be very similar at two successive steps or at fully symmetrical position in space. However, it is difficult in a stirred reactor to capture the same crystal at the specific position or symmetrical position. Based on this situation, we assumed that the projection generated at specific rotation angle was unique. In this case, we can use the similar method to reconstruct $3 \mathrm{D}$ size of dynamic crystals as static crystal.

\subsection{Image Segmentation Method}

The multi-scale image analysis software of PharmaVision (Qingdao) Intelligent Technology Ltd, SHAPE, was used to extract crystals from the image background. Key steps of the image segmentation algorithm were illustrated in literature [37] [38] so will not be repeated here. The processed images were stored in the format of pixel coordinates, i.e., all the points on the images including sampling signature were the pixel coordinates, which cannot be used to directly calculate the Fourier descriptors (FDs). The pixel coordinates can be transformed to the Cartesian coordinates based on the magnification $(2 x)$ and the size of each pixel (pixelated images with a resolution of $4.65 \mu \mathrm{m} /$ pixel). In this work, all the programs were written in MATLAB, and calculated by high performance computing platform $\left(20\right.$ computer codes, $2^{\star}$ Opteron 6000 processor, 12 processing core, $2.4 \mathrm{GHz}$ and $48 \mathrm{~Gb}$ Ram running Rocks 6.0 operation system based on CentOS 6.2) in South China University of Technology (SCUT). 


\section{Results and Discussion}

\subsection{Preliminary Analysis of the Images Captured in Experiments}

The sampling frequency was set to taking three pairs of images per second, hence in total 5400 image pairs were recorded in 30 minutes. Figure S1 shows examples of images taken immediately after nucleation (Figure S1(a) and Figure S1(b)). It is apparent that the images in Figure S1(a) and Figure S1(b) are too small to be able to construct the 3D shape of crystals. Figure S2 shows examples of images over a time window of about 7 seconds, from $17 \mathrm{~h} 15 \mathrm{~min} 37$ sec $102 \mathrm{~ms}$ to $17 \mathrm{~h} 15 \mathrm{~min} 43 \mathrm{sec} 797 \mathrm{~ms}$.

Some crystals in Figure S2 images were small, overlapped, or having blur external contour. Of course, these particles in the images can still be processed through multi-segmentation algorithm, and their FDs and radii calculated, and to find a $3 \mathrm{D}$ size by matching with the projections in the database. But the errors are likely large.

\subsection{Illustration of 3D Crystal Shape Reconstruction}

Based on the above preliminary analysis of the images captured, a strategy for illustrating crystal shape reconstruction in this section was used:

1) $3 \mathrm{D}$ crystal shape reconstruction was performed for only selected crystals in an image pair.

2) In order to reflect crystals' $3 \mathrm{D}$ size change with time during the crystallization, crystals in images taken in a time window of 7 seconds (written as 7 s) were analyzed together. The first time window of $7 \mathrm{~s}$ was given a new time in the new time axis as the first second, i.e., $1 \mathrm{~s}$. The first time window, i.e., the time window at $1 \mathrm{~s}$ in the new time system, was starting at $17 \mathrm{~h} 15 \mathrm{~min} 39 \mathrm{sec} 96 \mathrm{~ms}$ plus 7 seconds. Within this 1st time window, i.e., at the new time system at $1 \mathrm{~s}$, the crystals that were selected for 3D shape reconstruction are shown in Figure 3. It needs to point out that the crystals in the image of Figure 3 were selected from the original images of this $7 \mathrm{~s}$ time window and put together; they have retained their original $\mathrm{x}-\mathrm{y}$ axes.

3) A moving window strategy was employed, i.e., the second time window started from $17 \mathrm{~h} 15 \mathrm{~min} 40 \mathrm{sec} 96 \mathrm{~ms}$ with a width of 7 seconds. In other words, to move to the next time window, images over 1 second were moved out of the window from left, and new images span 1 second were added from the right side of the window. In this study, in total for 1316 crystals of potash alum, their 3D size and shape were reconstructed.

Figures 3-10 show the images at four different times representing time windows at $\mathrm{t}=1 \mathrm{~s}, 126 \mathrm{~s}, 1078 \mathrm{~s}$ and $1645 \mathrm{~s}$, processed images and the 3D reconstructed crystal shape. As is known, particles within focal length of the cameras were clear, otherwise particles were blurred. To reduce their effects to the maximum extent, the LED source was set strong power to provide sufficient light intensity to remove vague particles. In practice, images were photographed with a finite resolution by a CCD-chip. The pixel coordinates of particles on the images 
determine their size. The position of the same particle on two images was not completely consistent because of two cameras with an angle. Therefore, to accurately match the particle, the difference between two pixel coordinates of the particle on the $\mathrm{X}$ and $\mathrm{Y}$ axis in two images were calibrated based on the calibration parameters (error and the difference of pixel coordinates) in advance according to the relative position of two cameras. Here we only present a few typical cases to illustrate this process.
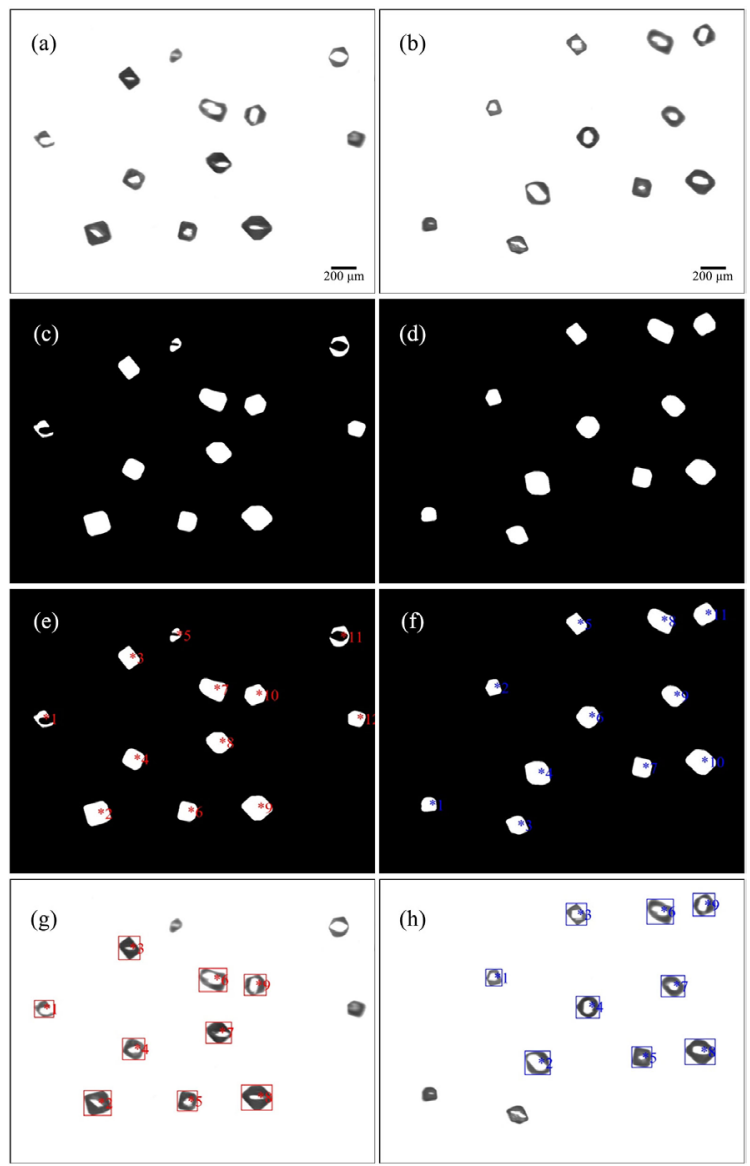

Figure 3. On-line images from the stereo vision imaging system at the time window $t=1 \mathrm{~s}$, (a) camera 1, (b) camera 2, the two images ((c) and (d)) processed by multi-segmentation method, all particles marked on the images ((e) and (f)), successfully matched particles on images $((\mathrm{g})$ and $(\mathrm{h}))$.

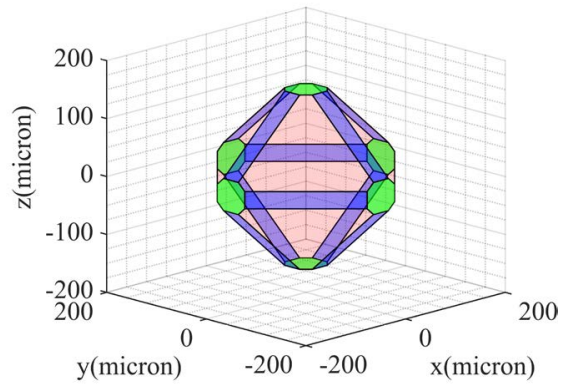

(a)

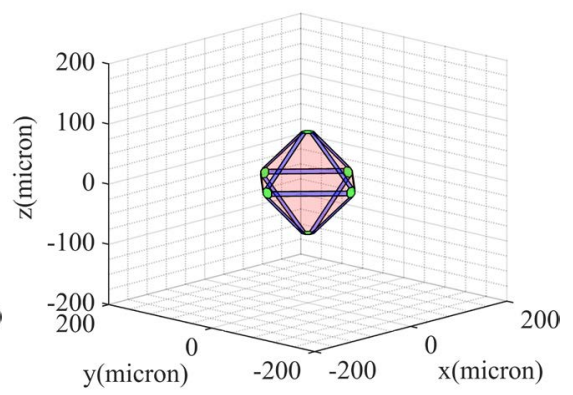

(b) 


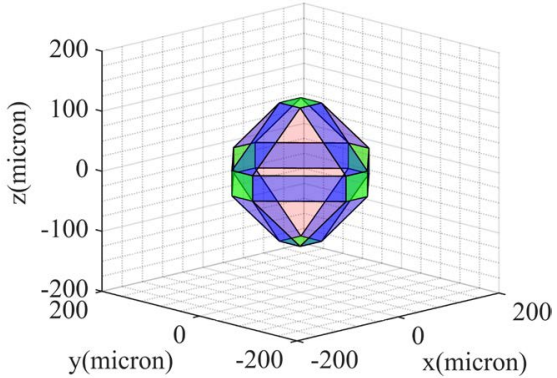

(c)

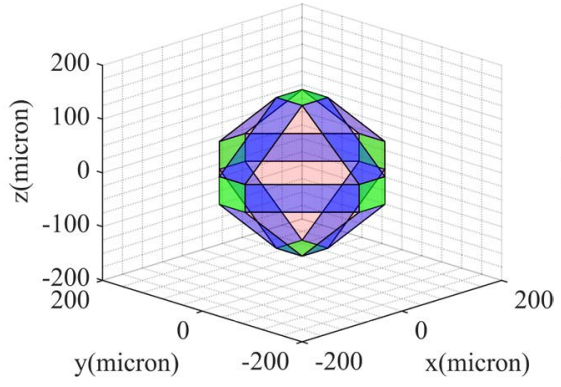

(e)

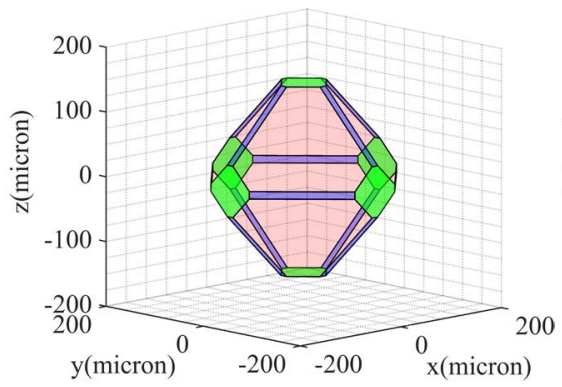

(g)

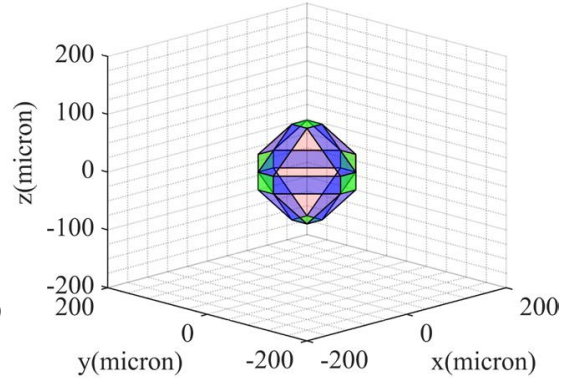

(d)

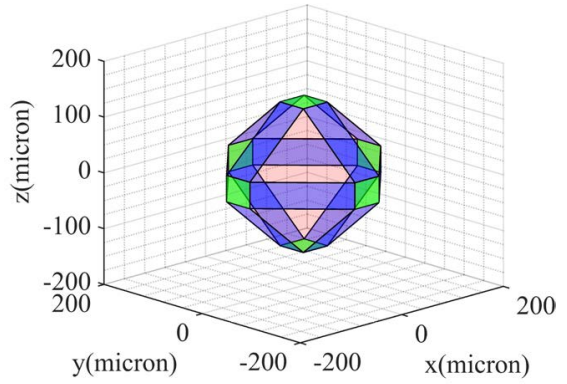

(f)

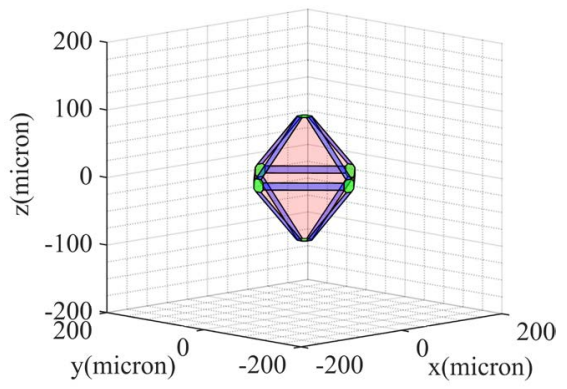

(h)

Figure 4. The $3 \mathrm{D}$ shapes of crystals No 2 to No 9 at the time window $\mathrm{t}=1 \mathrm{~s}$, the number of a crystal is consistent with Figure 3(g) and Figure 3(h). (a)-No 2; (b)-No 3; (c)-No 4; (d)-No 5; (e)-No 6; (f)-No 7; (g)-No 8; (h)-No 9.

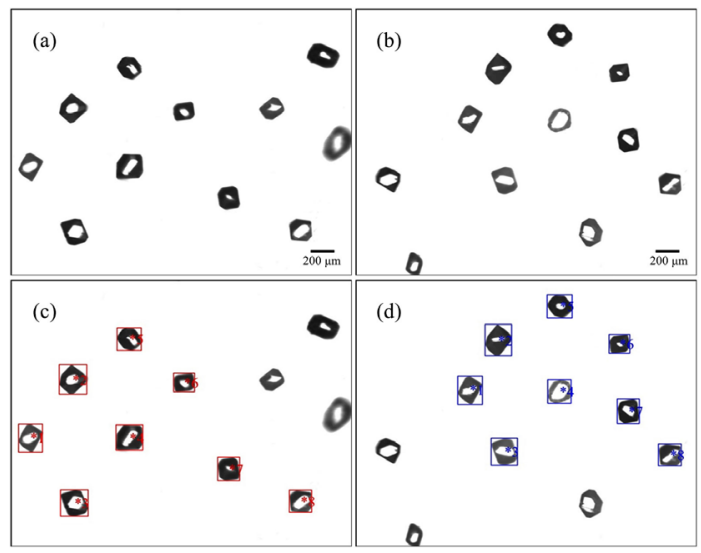

Figure 5. On-line images from the stereo vision imaging system at the time window $t=$ $126 \mathrm{~s}$, (a) camera 1, (b) camera 2, the two images successfully matched particles on images ((c) and (d)). 
As shown in Figure 3(e) and Figure 3(f), there were 12 particles marked on the images. Next, 9 pairs of particles were matched based on the pixel positions in Figures 3(g) and Figures 3(h). However, the boundary information of the particle marked as No 1 on the image from camera 1 is missing, so it was not considered. Other crystals, numbered 2 to 9 were successfully reconstructed (see Figure 4 ) in which the 3D shape of each of the crystals No. 2 to No. 9 was shown.

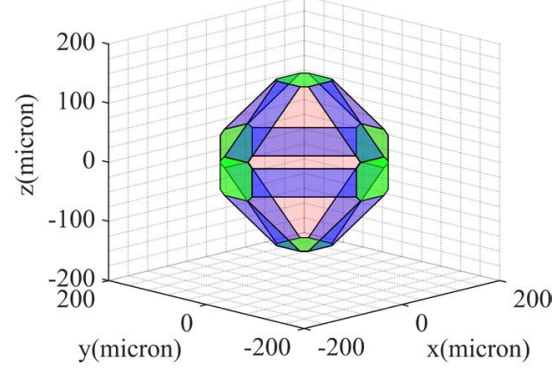

(a)

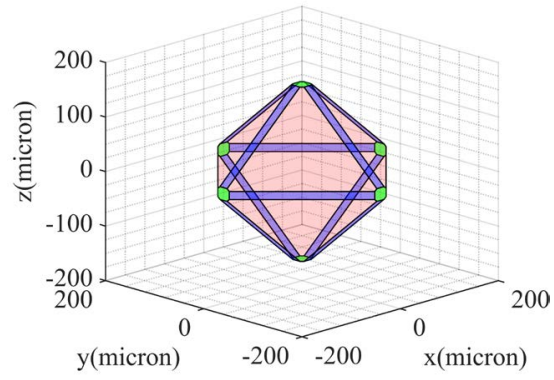

(c)

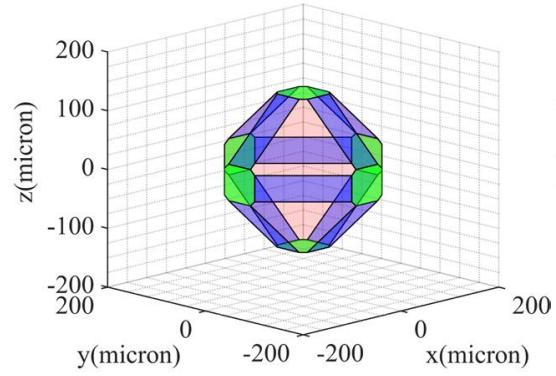

(e)

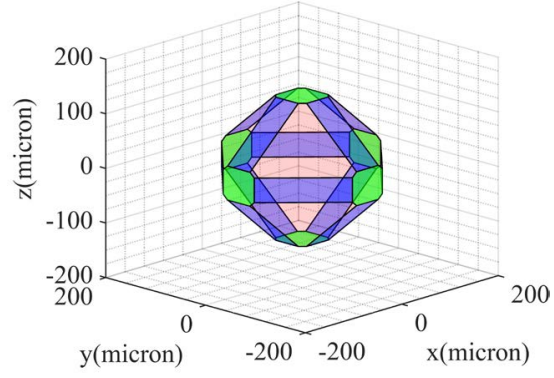

(g)

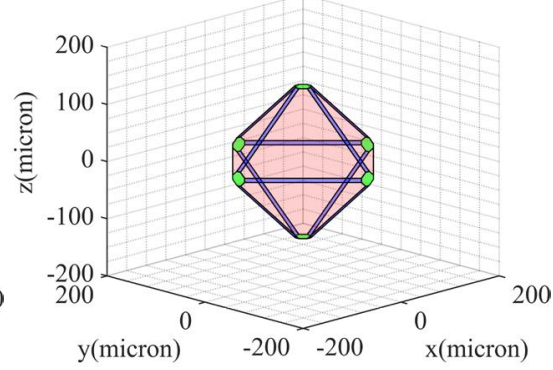

(b)

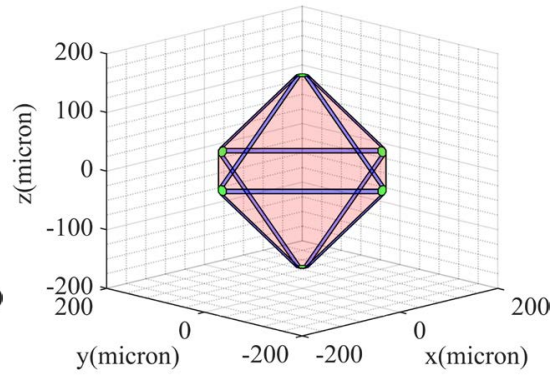

(d)

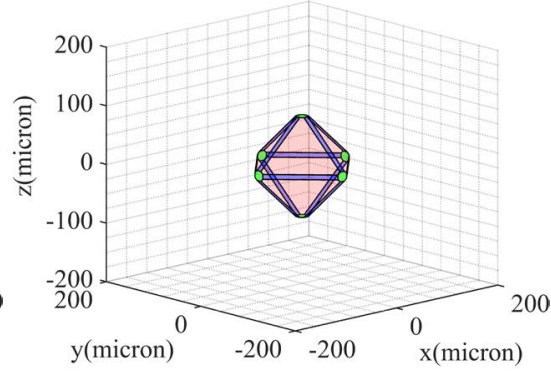

(f)

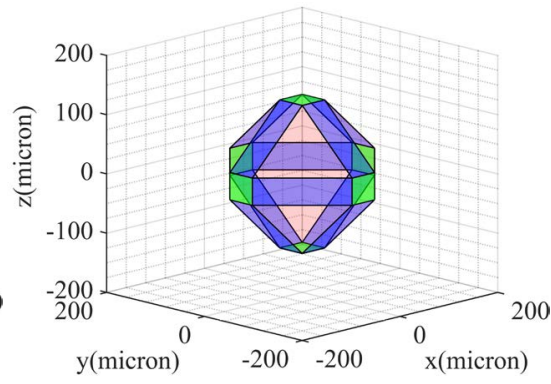

(h)

Figure 6. The $3 \mathrm{D}$ shapes of crystals at the time window $\mathrm{t}=126 \mathrm{~s}$, the number of a crystal is consistent with Figure 5(c) and Figure 5(d). 


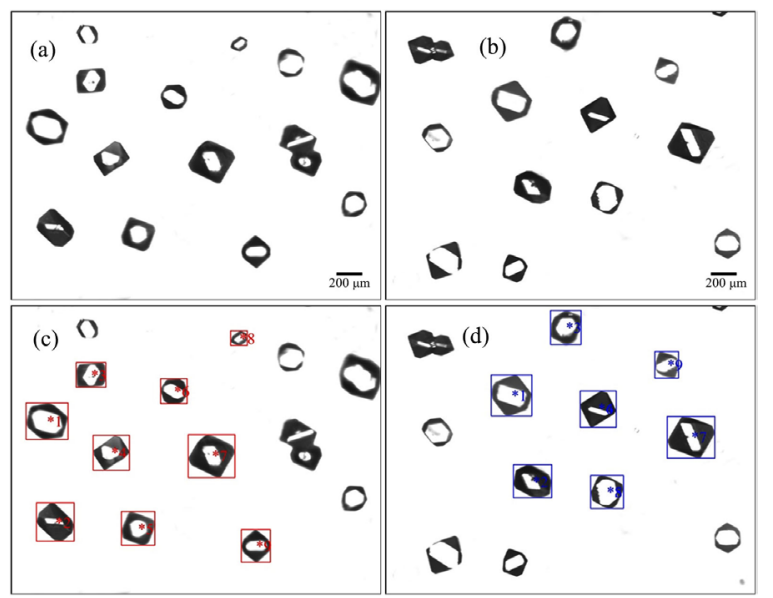

Figure 7. On-line images from the stereo vision imaging system at the time window $t=$ $1078 \mathrm{~s}$, (a) camera 1, (b) camera 2, the two images successfully matched particles on images ((c) and (d)).

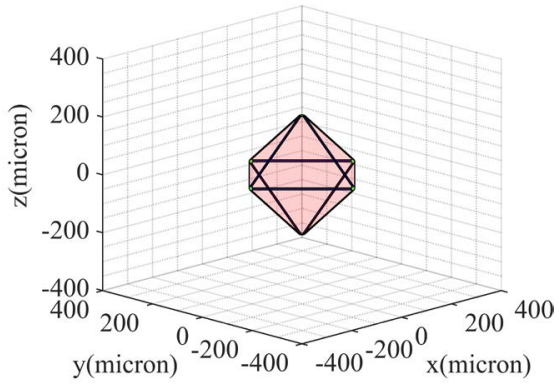

(a)

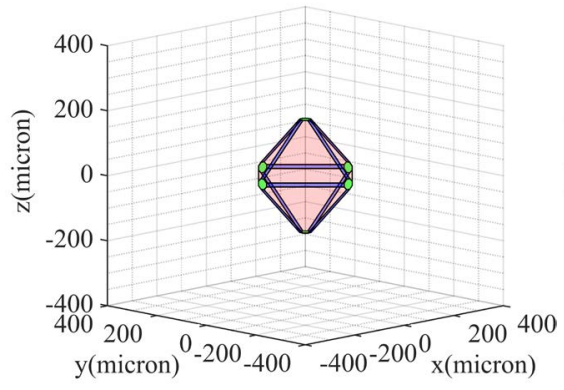

(c)

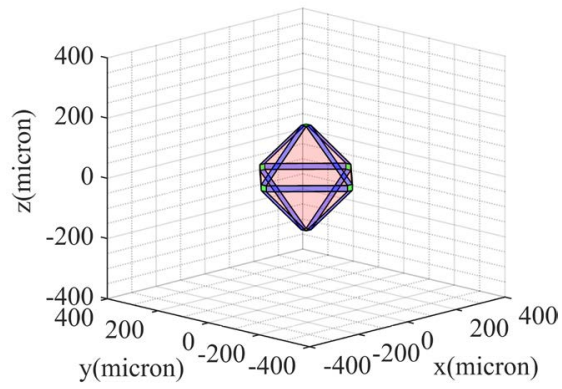

(e)

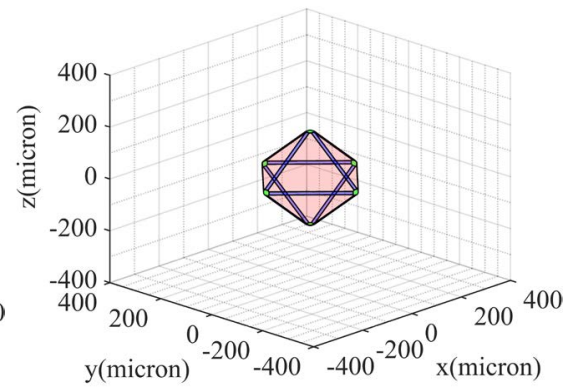

(b)

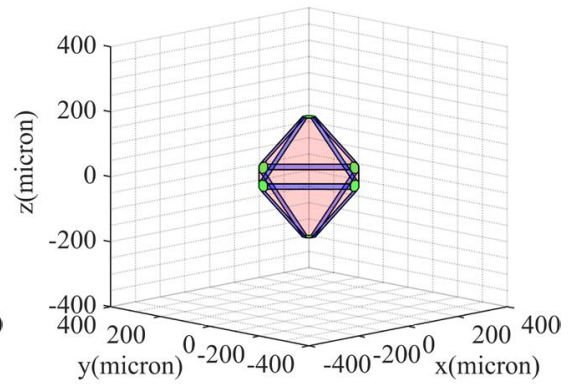

(d)

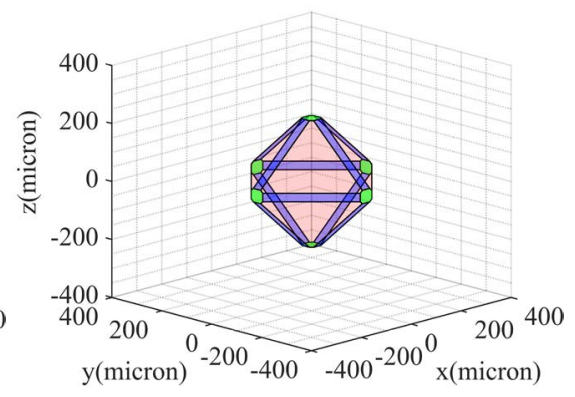

(f)

Figure 8 . The $3 \mathrm{D}$ shapes of crystals at the time window $\mathrm{t}=1078 \mathrm{~s}$, the number of a crystal is consistent with Figure 7 (c) and Figure 7(d). 


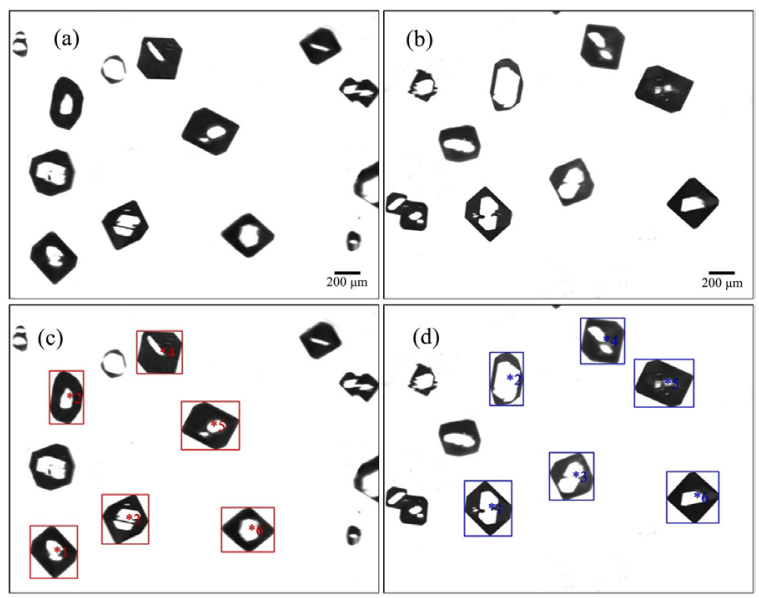

Figure 9. On-line images from the stereo vision imaging system at the time window $t=$ $1645 \mathrm{~s}$, (a) camera 1, (b) camera 2, the two images successfully matched particles on images ((c) and (d)).

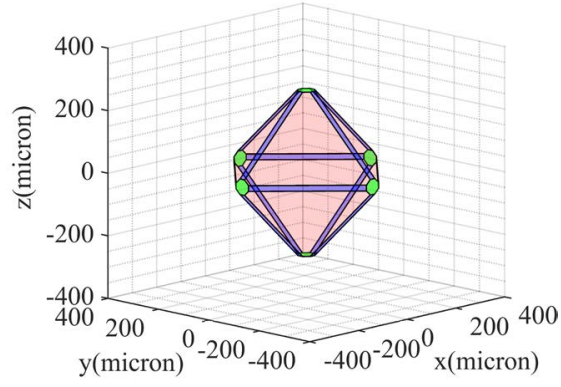

(a)

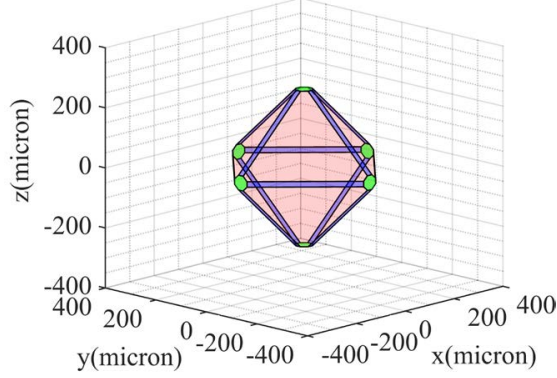

(c)

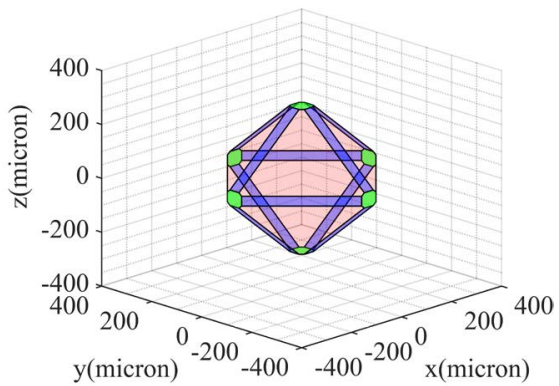

(e)

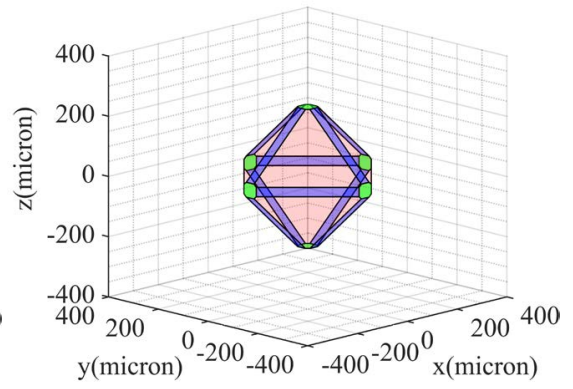

(b)

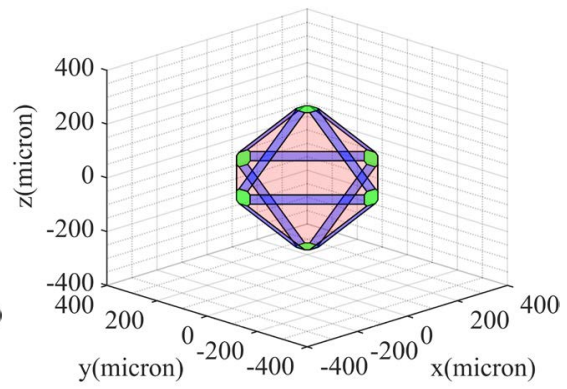

(d)

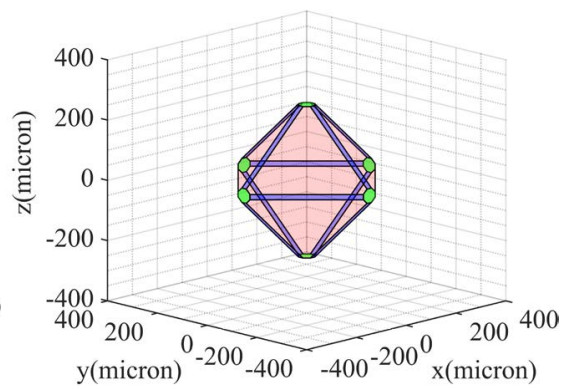

(f)

Figure 10. The $3 \mathrm{D}$ shapes of crystals at the time window $t=1645 \mathrm{~s}$, the number of a crystal is consistent with Figure 9(c) and Figure 9(d). 
In Figure 4, shapes of eight crystals were successfully reconstructed, including the multidimensional sizes written on each crystal as the normal distances of the three featured faces, $x, y, z$. It can be seen that the shape of a crystal depends on the relative ratio between the three sizes $\mathrm{x}, \mathrm{y}, \mathrm{z}$. For example, crystals No 3 and 9 have similar ratios for $x: y: z$, so they have the similar shapes (small $\{100\}$ and $\{110\}$ with hexagon, large $\{111\}$ hexagon) though they have different dimensional sizes. Crystals numbered 4, 5, 6 and 7 crystals have similar x:y:z ratios, so they have similar shapes ( $\{100\}$ and $\{110\}$ with rectangle, $\{111\}$ with triangle) despite they have different dimensional sizes. The dimensional sizes of the number 2 crystal are the maximum $(x=25.43 \mu \mathrm{m}, \mathrm{y}=35.46 \mu \mathrm{m}, \mathrm{z}=28.94 \mu \mathrm{m})$, and the No 5 crystal has the minimum dimensional sizes with $\mathrm{x}=12.33 \mu \mathrm{m}, \mathrm{y}=19.50 \mu \mathrm{m}$ and $\mathrm{z}=15.91 \mu \mathrm{m}$.

Similar observations can be made for other three time windows at $t=126 \mathrm{~s}$, $1078 \mathrm{~s}$ and $1645 \mathrm{~s}$ (Figures 5-10). In addition, the reconstructed crystal sizes generally speaking became larger from $t=1 \mathrm{~s}$ to $1645 \mathrm{~s}$, which demonstrates crystals grow gradually during the cooling crystallization. Obviously, getting larger or not for the crystals should be based on statistical data, as will be provided later.

\subsection{D Crystal Shape Evolution on a Statistical Basis}

Obviously, it is impossible to capture the same crystals at different times due to the continuous motion and rotation of the suspension in a stirred reactor. Therefore, the crystal size obtained at a particular time cannot well reflect the population of crystal size in the reactor. Even using the moving window approach described above, if the window width is small like 7 seconds above, it cannot reflect the statistical information.

In this section, the width of a time window is set as $30 \mathrm{~s} \mathrm{(a} \mathrm{time} \mathrm{window} \mathrm{per}$ four images). As a new image is added into the moving window each time, the earliest image in the window will be taken out to keep the window width at $30 \mathrm{~s}$. All the particles in the current time window are analyzed to provide the size distribution. Figure $\mathrm{S} 3$ shows variation of growth rates and the averaged normal distances, $x, y, z$ with time through analyzing images from reconstructed crystal mean size, respectively.

To more precisely display variety of the mean size with time, larger window time width to $60 \mathrm{~s}$ at three different times was chosen. Figures 11-13 show the predicted mean size distributions in the face $\{111\},\{110\}$ and $\{100\}$ at $126 \mathrm{~s}, 1078$ s, $1645 \mathrm{~s}$. It can be seen that the averaged normal distances of three characteristic faces $\{111\},\{110\}$ and $\{100\}$ successively increase at three times. Furthermore, based on the reconstructed 3D shape, apparently, the areas of faces $\{100\}$ (green) and $\{110\}$ (blue) slowly decrease, especially face $\{100\}$, by the contrast, the area of $\{111\}$ (pink) becomes larger with the time, which is good agreement with images captured through stereo cameras. From Figure 3(a) and Figure 3(b) to Figure 9(a) and Figure 9(b), it can be seen that some edges of the 2D projec- 
tions became smaller as a result of smaller area of face $\{100\}$. It indicated that the growth rate of face $\{111\}$ may be the slowest, while growth rate of face $\{100\}$ may be the fastest in the cooling crystallization.

\subsection{Estimation of Face Specific Growth Kinetics}

Figure $\mathrm{S} 3$ shows the mean distributions of normal distances ( $\mathrm{x}, \mathrm{y}$ and $\mathrm{z}$ ) of three individual faces $\{111\},\{100\}$ and $\{110\}$. It can be seen that the normal distances of individual faces grew with time, $t$, and a second order polynomial function was used to curve-fit them with $\mathrm{R}^{2}$ being over 0.90 :

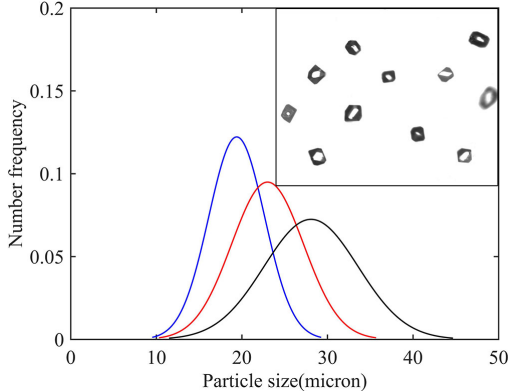

(a)

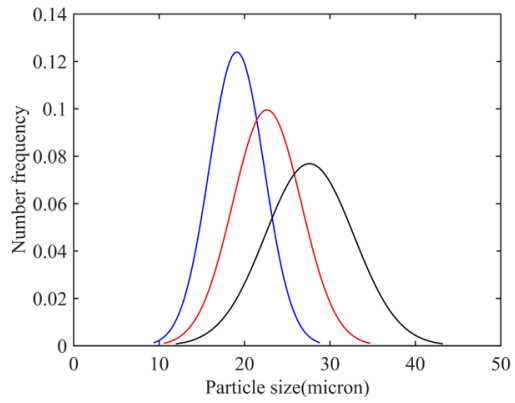

(c)

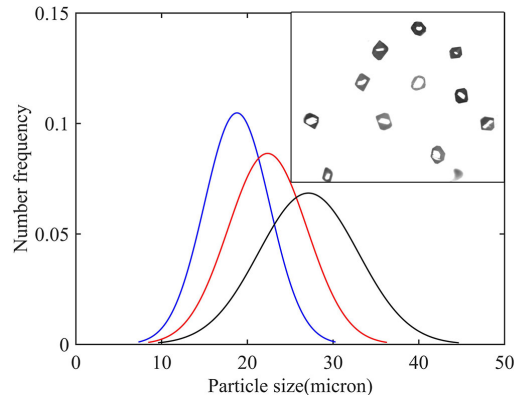

(b)

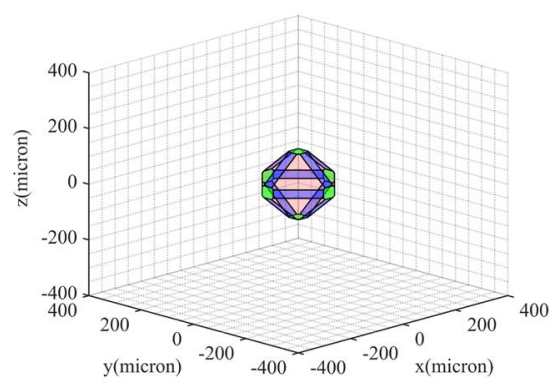

(d)

Figure 11. The mean size distribution in three featured faces (solid lines: blue- $\{111\}$ face, red- $\{110\}$ face, black- $\{100\}$ face,) average previous $60 \mathrm{~s}$ at $126 \mathrm{~s}$, (a) single camera 1 , mean size $19.39 \mu \mathrm{m}$ in $\{111\}$ face, $22.99 \mu \mathrm{m}$ in $\{110\}$ face and $28.08 \mu \mathrm{m}$ in $\{100\}$; (b) single camera 2 , mean size $18.79 \mu \mathrm{m}$ in $\{111\}$ face, $22.36 \mu \mathrm{m}$ in $\{110\}$ face and $27.12 \mu \mathrm{m}$ in $\{100\}$; (c) stereo camera, mean size $19.09 \mu \mathrm{m}$ in $\{111\}$ face, $22.63 \mu \mathrm{m}$ in $\{110\}$ face and $27.60 \mu \mathrm{m}$ in $\{100\}$ face; $(d)$ reconstructed 3D shape, pink- $\{111\}(\mathrm{x})$, green- $\{100\}(y)$, blue- $\{110\}(\mathrm{z})$.

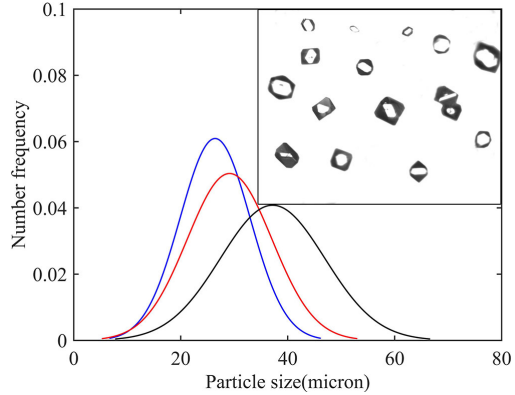

(a)

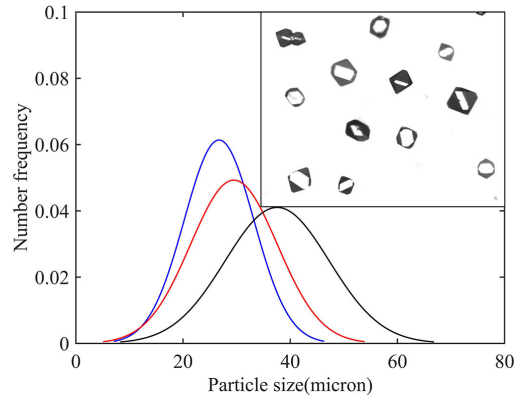

(b) 


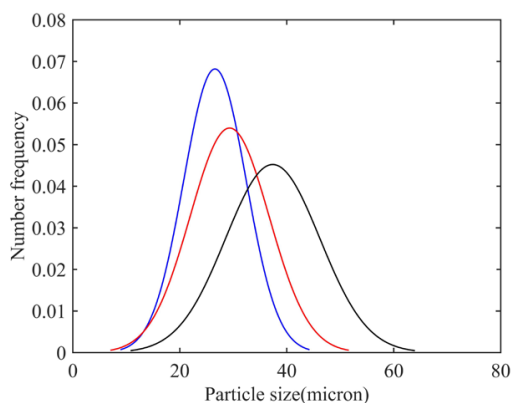

(c)

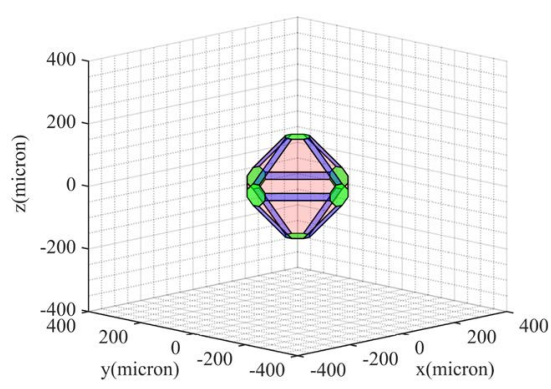

(d)

Figure 12. The mean size distribution in three featured faces (solid lines: blue- $\{111\}$ face, red-\{110\} face, black- $\{100\}$ face,) average previous $60 \mathrm{~s}$ at $1078 \mathrm{~s}$, (a) single camera 1 , mean size $26.43 \mu \mathrm{m}$ in $\{111\}$ face, $29.13 \mu \mathrm{m}$ in $\{110\}$ face and $37.18 \mu \mathrm{m}$ in $\{100\}$; (b) single camera 2 , mean size $26.72 \mu \mathrm{m}$ in $\{111\}$ face, $29.49 \mu \mathrm{m}$ in $\{110\}$ face and $37.56 \mu \mathrm{m}$ in $\{100\}$; (c) stereo camera, mean size $26.57 \mu \mathrm{m}$ in $\{111\}$ face, $29.31 \mu \mathrm{m}$ in $\{110\}$ face and $37.37 \mu \mathrm{m}$ in $\{100\}$ face; (d) reconstructed $3 D$ shape, pink- $\{111\}(\mathrm{x})$, green- $\{100\}(y)$, blue- $\{110\}(\mathrm{z})$.

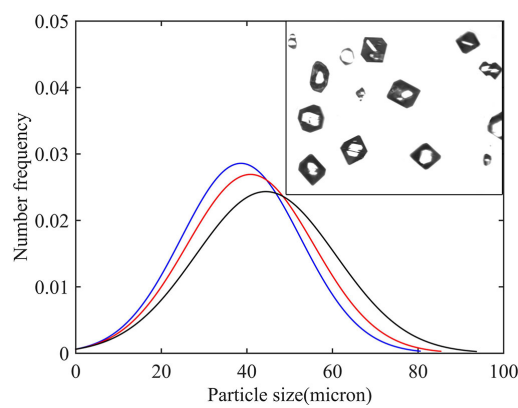

(a)

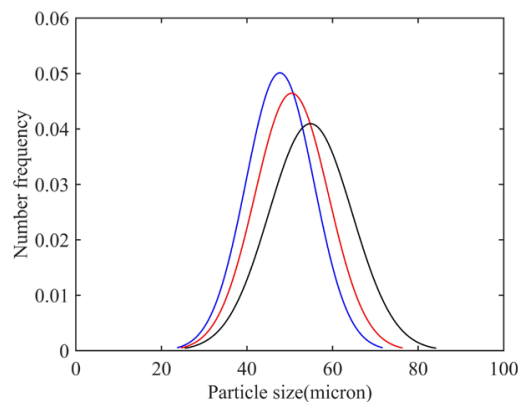

(c)

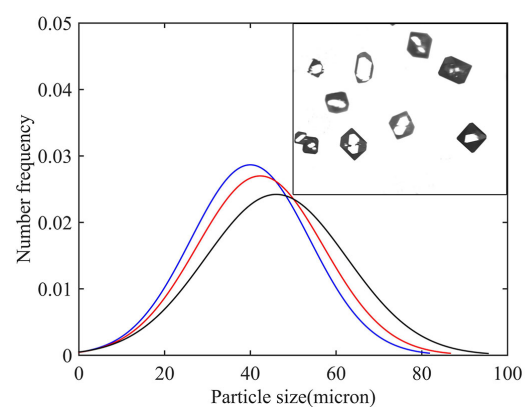

(b)

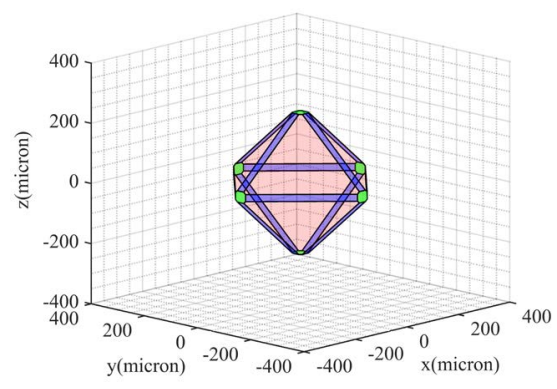

(d)

Figure 13. The mean size distribution in three featured faces (solid lines: blue- $\{111\}$ face, red-\{110\} face, black- $\{100\}$ face,) average previous $60 \mathrm{~s}$ at $1645 \mathrm{~s}$, (a) single camera 1 , mean size $38.61 \mu \mathrm{m}$ in $\{111\}$ face, $40.84 \mu \mathrm{m}$ in $\{110\}$ face and $44.42 \mu \mathrm{m}$ in $\{100\}$; (b) single camera 2 , mean size $39.99 \mu \mathrm{m}$ in $\{111\}$ face, $42.30 \mu \mathrm{m}$ in $\{110\}$ face and $46.04 \mu \mathrm{m}$ in $\{100\}$; (c) stereo camera, mean size $47.69 \mu \mathrm{m}$ in $\{111\}$ face, $50.45 \mu \mathrm{m}$ in $\{110\}$ face and $54.85 \mu \mathrm{m}$ in $\{100\}$ face; (d) reconstructed 3D shape, pink- $\{111\}(\mathrm{x})$, green- $\{100\}$ (y), blue- $\{110\}(\mathrm{z})$.

$$
\begin{aligned}
& x=\left(0.0004 \times t^{2}-0.0599 \times t+21.922\right) \times 10^{-6} \\
& y=\left(0.0008 \times t^{2}+0.0061 \times t+27.659\right) \times 10^{-6} \\
& z=\left(0.0006 \times t^{2}-0.0718 \times t+25.391\right) \times 10^{-6}
\end{aligned}
$$


Equations (1)-(3) were used to obtain growth rates of three individual faces. As shown in Figure S3(b), the obtained growth rates have a linear relationship with time. The crystal growth rates of three individual faces against the relative supersaturation can be obtained (Equations (4)-(6)).

$$
\begin{aligned}
G_{\{111\}} & =9.242 \times 10^{-7} \times \sigma^{2.16} \\
G_{\{100\}} & =1.849 \times 10^{-6} \times \sigma^{2.16} \\
G_{\{110\}} & =1.386 \times 10^{-6} \times \sigma^{2.16}
\end{aligned}
$$

It is worth noting that the 3D shape of complex crystals in a stirred tank was firstly reconstructed via stereo imaging system and image analysis techniques, which provides a feasible reconstruction approach method for obtaining 3D shape information of other compounds including potash alum in the future. In addition, the method developed here was used to estimate the growth rate of three individual faces of potash alum, especially the growth rate of faces $\{100\}$ and $\{110\}$, which was rarely reported in literatures because of difficult to measure and estimate. The results show that the growth rate of $\{100\}$ is the fastest, while the slowest is face $\{111\}$, this trend observed for dynamic crystals is consistent with what was found for static crystals in previous work [3].

\section{Concluding Remarks}

In this paper, the stereo imaging camera model for crystal 3D shape reconstruction was applied to online estimation of faceted growth kinetics of potash alum crystals growing in a stirred tank crystallizer. The crystal size and shape distribution (CSSD) was estimated based on statistical information obtained from moving windows. Moreover, the result revealed that faces $\{100\}$ and $\{111\}$ are the fastest and slowest growing faces, respectively. The promising result obtained provides a valuable approach for monitoring the 3D CSSD. It is noted that in stirred tank crystallizers, there are still some difficulties and challenges such as blur, overlapped and too small particles in the images, which should be addressed in the future.

\section{Acknowledgements}

Financial support from the National Natural Science Foundation of China (NNSFC) (grant references: 91434126, 61633006 and 21706075), the Natural Science Foundation of Guangdong Province (grant reference: 2014A030313228, 2018A030313263), and the Guangdong Provincial Science and Technology Projects under the Scheme of Applied Science and Technology Research Special Funds (grant reference: 2015B020232007) is acknowledged. Thanks are also due to Dr. Jianguo Cao of Pharmavision (Qingdao) Intelligent Technology Ltd. for providing instrument and support to the imaging and image analysis system.

\section{Conflicts of Interest}

The authors declare no conflicts of interest regarding the publication of this paper. 


\section{References}

[1] Zhang, R., Ma, C.Y., Liu, J.J. and Wang, X.Z. (2015) On-Line Measurement of the Real Size and Shape of Crystals in Stirred Tank Crystalliser Using Non-Invasive Stereo Vision Imaging. Chemical Engineering Science, 137, 9-21. https://doi.org/10.1016/j.ces.2015.05.053

[2] Wu, K., Ma, C.Y., Liu, J.J., Zhang, Y. and Wang, X.Z. (2016) Measurement of Crystal Face Specific Growth Kinetics. Crystal Growth \& Design, 16, 4855-4868. https://doi.org/10.1021/acs.cgd.6b00189

[3] Ma, C.Y., Liu, J.J. and Wang, X.Z. (2016) Stereo Imaging of Crystal Growth. AIChE Journal, 62, 18-25. https://doi.org/10.1002/aic.15041

[4] Zhang, R., Ma, C.Y., Liu, J.J., Zhang, Y., Liu, Y.J. and Wang, X.Z. (2017) Stereo Imaging Camera Model for 3D Shape Reconstruction of Complex Crystals and Estimation of Facet Growth Kinetics. Chemical Engineering Science, 160, 171-182. https://doi.org/10.1016/j.ces.2016.11.029

[5] Ma, C.Y., Liu, J.J. and Wang, X.Z. (2016) Measurement, Modelling, and Closed-Loop Control of Crystal Shape Distribution: Literature Review and Future Perspectives. Particuology, 26, 1-18. https://doi.org/10.1016/j.partic.2015.09.014

[6] Wang, X.Z., Roberts, K.J. and Ma, C. (2008) Crystal Growth Measurement Using 2D and 3D Imaging and the Perspectives for Shape Control. Chemical Engineering Science, 63, 1173-1184. https://doi.org/10.1016/j.ces.2007.07.018

[7] Zhang, Y., Liu, J.J., Zhang, L., De Anda, J.C. and Wang, X.Z. (2016) Particle Shape Characterisation and Classification Using Automated Microscopy and Shape Descriptors in Batch Manufacture of Particulate Solids. Particuology, 24, 61-68. https://doi.org/10.1016/j.partic.2014.12.012

[8] Li, R.F., Thomson, G.B., White, G., Wang, X.Z., De Anda, J.C. and Roberts, K.J. (2006) Integration of Crystal Morphology Modeling and On-Line Shape Measurement. AIChE Journal, 52, 2297-2305. https://doi.org/10.1002/aic.10818

[9] Borchert, C., Temmel, E., Eisenschmidt, H., Lorenz, H., Seidel-Morgenstern, A. and Sundmacher, K. (2014) Image-Based in Situ Identification of Face Specific Crystal Growth Rates from Crystal Populations. Crystal Growth \& Design, 14, 952-971. https://doi.org/10.1021/cg401098x

[10] Kempkes, M., Vetter, T. and Mazzotti, M. (2010) Measurement of 3D Particle Size Distributions by Stereoscopic Imaging. Chemical Engineering Science, 65, 1362-1373. https://doi.org/10.1016/j.ces.2009.10.008

[11] Schorsch, S., Vetter, T. and Mazzotti, M. (2012) Measuring Multidimensional Particle Size Distributions during Crystallization. Chemical Engineering Science, 77, 130-142. https://doi.org/10.1016/j.ces.2011.11.029

[12] Schorsch, S., Ochsenbein, D.R., Vetter, T., Morari, M. and Mazzotti, M. (2014) High Accuracy Online Measurement of Multidimensional Particle Size Distributions during Crystallization. Chemical Engineering Science, 105, 155-168. https://doi.org/10.1016/j.ces.2013.11.003

[13] Schorsch, S., Hours, J.-H., Vetter, T., Mazzotti, M. and Jones, C.N. (2015) An Optimization-Based Approach to Extract Faceted Crystal Shapes from Stereoscopic Images. Computers \& Chemical Engineering, 75, 171-183. https://doi.org/10.1016/j.compchemeng.2015.01.016

[14] Huo, Y., Liu, T., Liu, H., Ma, C.Y. and Wang, X.Z. (2016) In-Situ Crystal Morphology Identification Using Imaging Analysis with Application to the L-Glutamic Acid Crystallization. Chemical Engineering Science, 148, 126-139. 
https://doi.org/10.1016/j.ces.2016.03.039

[15] Huo, Y., Liu, T., Wang, X.Z., Ma, C.Y. and Ni, X. (2017) Online Detection of Particle Agglomeration during Solution Crystallization by Microscopic Double-View Image Analysis. Industrial \& Engineering Chemistry Research, 56, 11257-11269. https://doi.org/10.1021/acs.iecr.7b02439

[16] Kovačević, T., Reinhold, A. and Briesen, H. (2014) Identifying Faceted Crystal Shape from Three-Dimensional Tomography Data. Crystal Growth \& Design, 14, 1666-1675. https://doi.org/10.1021/cg401780p

[17] Kovačević, T., Schock, J., Pfeiffer, F. and Briesen, H. (2016) Shape Identification of Primary Particles in Potash Alum Aggregates Using Three-Dimensional Tomography Data. Crystal Growth \& Design, 16, 2685-2699. https://doi.org/10.1021/acs.cgd.5b01806

[18] Kovačević, T., Wiedmeyer, V., Schock, J., Voigt, A., Pfeiffer, F., Sundmacher, K. and Briesen, H. (2017) Disorientation Angle Distribution of Primary Particles in Potash Alum Aggregates. Journal of Crystal Growth, 467, 93-106. https://doi.org/10.1016/j.jcrysgro.2017.03.026

[19] Indhumathi, C., Cai, Y.Y., Guan, Y.Q. and Opas, M. (2011) An Automatic Segmentation Algorithm for 3D Cell Cluster Splitting Using Volumetric Confocal Images. Journal of Microscopy, 243, 60. https://doi.org/10.1111/j.1365-2818.2010.03482.x

[20] Singh, M.R., Chakraborty, J., Nere, N., Tung, H.H., Bordawekar, S. and Ramkrishna, D. (2012) Image-Analysis-Based Method for 3D Crystal Morphology Measurement and Polymorph Identification Using Confocal Microscopy. Crystal Growth \& Design, 12, 3735-3748. https://doi.org/10.1021/cg300547w

[21] Stock, S. (2009) Micro-Computed Tomography. CRC Press, Taylor \& Francis Group, Boca Raton.

[22] Erdoğan, S.T., Nie, X., Stutzman, P.E. and Garboczi, E.J. (2010) Micrometer-Scale 3-D Shape Characterization of Eight Cements: Particle Shape and Cement Chemistry, and the Effect of Particle Shape on Laser Diffraction Particle Size Measurement. Cement \& Concrete Research, 40, 731-739. https://doi.org/10.1016/j.cemconres.2009.12.006

[23] Frisullo, P., Barnabà, M., Navarini, L. and Del Nobile, M.A. (2012) Coffea arabica Beans Microstructural Changes Induced by Roasting: An X-Ray Microtomographic Investigation. Journal of Food Engineering, 108, 232-237. https://doi.org/10.1016/j.jfoodeng.2011.07.036

[24] Jerram, D.A., Mock, A., Davis, G.R., Field, M. and Brown, R.J. (2009) 3D Crystal Size Distributions: A Case Study on Quantifying Olivine Populations in Kimberlites. Lithos, 112, 223-235. https://doi.org/10.1016/j.lithos.2009.05.042

[25] Redenbach, C., Ohser-Wiedemann, R., Löffler, R., Bernthaler, T. and Nagel, A. (2011) Characterization of Powders Using Micro Computed Tomography. Particle \& Particle Systems Characterization, 28, 3-12. https://doi.org/10.1002/ppsc.200900088

[26] Dandekar, P., Kuvadia, Z.B. and Doherty, M.F. (2013) Engineering Crystal Morphology. Annual Review of Materials Research, 43, 359-386. https://doi.org/10.1146/annurev-matsci-071312-121623

[27] Klapper, H., Becker, R.A., Schmiemann, D. and Faber, A. (2002) Growth-Sector Boundaries and Growth-Rate Dispersion in Potassium Alum Crystals. Crystal Research and Technology, 37, 747-757. https://doi.org/10.1002/1521-4079(200207)37:7<747::AID-CRAT747>3.0.CO;2-2

[28] Ma, C.Y., Wang, X.Z. and Roberts, K.J. (2008) Morphological Population Balance 
for Modeling Crystal Growth in Face Directions. AIChE Journal, 54, 209-222. https://doi.org/10.1002/aic.11365

[29] Ristic, R.I., Shekunov, B. and Shewood, J.N. (1996) Long and Short Period Growth Rate Variations in Potash Alum Crystals. Journal of Crystal Growth, 160, 330-336. https://doi.org/10.1016/0022-0248(95)00741-5

[30] Ristic, R.I., Shekunov, B.Y. and Sherwood, J.N. (1997) The Influence of Synchrotron Radiation-Induced Strain on the Growth and Dissolution of Brittle and Ductile Materials. Journal of Crystal Growth, 179, 205-212. https://doi.org/10.1016/S0022-0248(97)00106-1

[31] Barrett, P. and Glennon, B. (2002) Characterizing the Metastable Zone Width and Solubility Curve Using Lasentec FBRM and PVM. Chemical Engineering Research and Design, 80, 799-805. https://doi.org/10.1205/026387602320776876

[32] Nollet, S., Hilgers, C. and Urai, J.L. (2006) Experimental Study of Polycrystal Growth from an Advecting Supersaturated Fluid in a Model Fracture. Geofluids, 6, 185-200. https://doi.org/10.1111/j.1468-8123.2006.00142.x

[33] Ma, C.Y. and Wang, X.Z. (2012) Model Identification of Crystal Facet Growth Kinetics in Morphological Population Balance Modeling of L-Glutamic Acid Crystallization and Experimental Validation. Chemical Engineering Science, 70, 22-30. https://doi.org/10.1016/j.ces.2011.05.042

[34] Ma, C.Y. and Wang, X.Z. (2012) Closed-Loop Control of Crystal Shape in Cooling Crystallization of L-Glutamic Acid. Journal of Process Control, 22, 72-81. https://doi.org/10.1016/j.jprocont.2011.10.007

[35] Wold, S., Sjöström, M. and Eriksson, L. (2001) PLS-Regression: A Basic Tool of Chemometrics. Chemometrics and Intelligent Laboratory Systems, 58, 109-130. https://doi.org/10.1016/S0169-7439(01)00155-1

[36] Wan, J., Wang, X.Z. and Ma, C.Y. (2009) Particle Shape Manipulation and Optimization in Cooling Crystallization Involving Multiple Crystal Morphological Forms. AIChE Journal, 55, 2049-2061. https://doi.org/10.1002/aic.11892

[37] Calderon De Anda, J., Wang, X.Z. and Roberts, K.J. (2005) Multi-Scale Segmentation Image Analysis for the In-Process Monitoring of Particle Shape with Batch Crystallisers. Chemical Engineering Science, 60, 1053-1065. https://doi.org/10.1016/j.ces.2004.09.068

[38] Wan, J., Ma, C.Y. and Wang, X.Z. (2008) A Method for Analyzing On-Line Video Images of Crystallization at High-Solid Concentrations. Particuology, 6, 9-15. https://doi.org/10.1016/j.cpart.2007.11.001 


\section{Appendix}

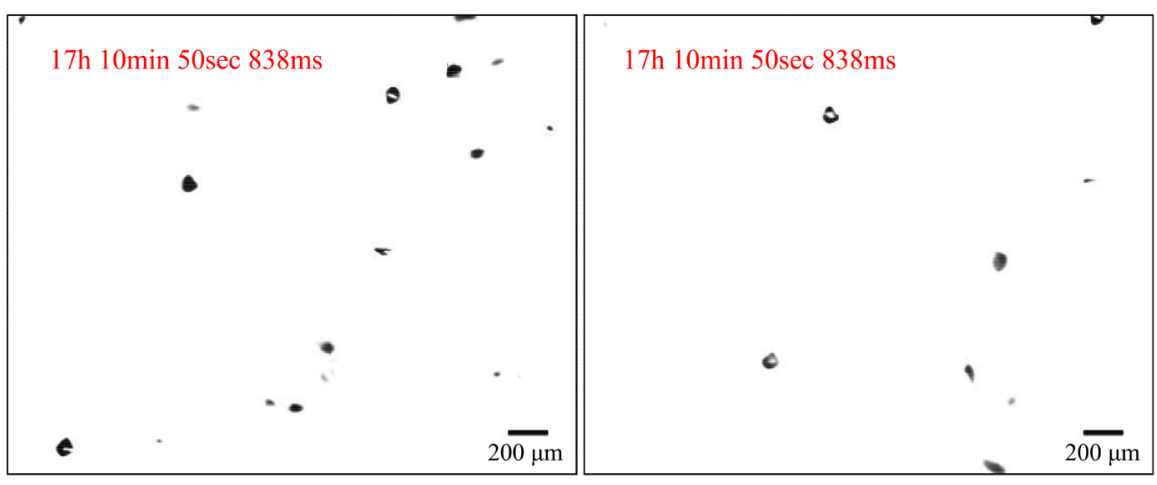

(a)

(b)

Figure S1. On-line images captured from a crystallization experiment of potash alum using stereo imaging system, camera 1 (left) and camera 2 (right), (a) and (b) crystals were firstly observed in the images.

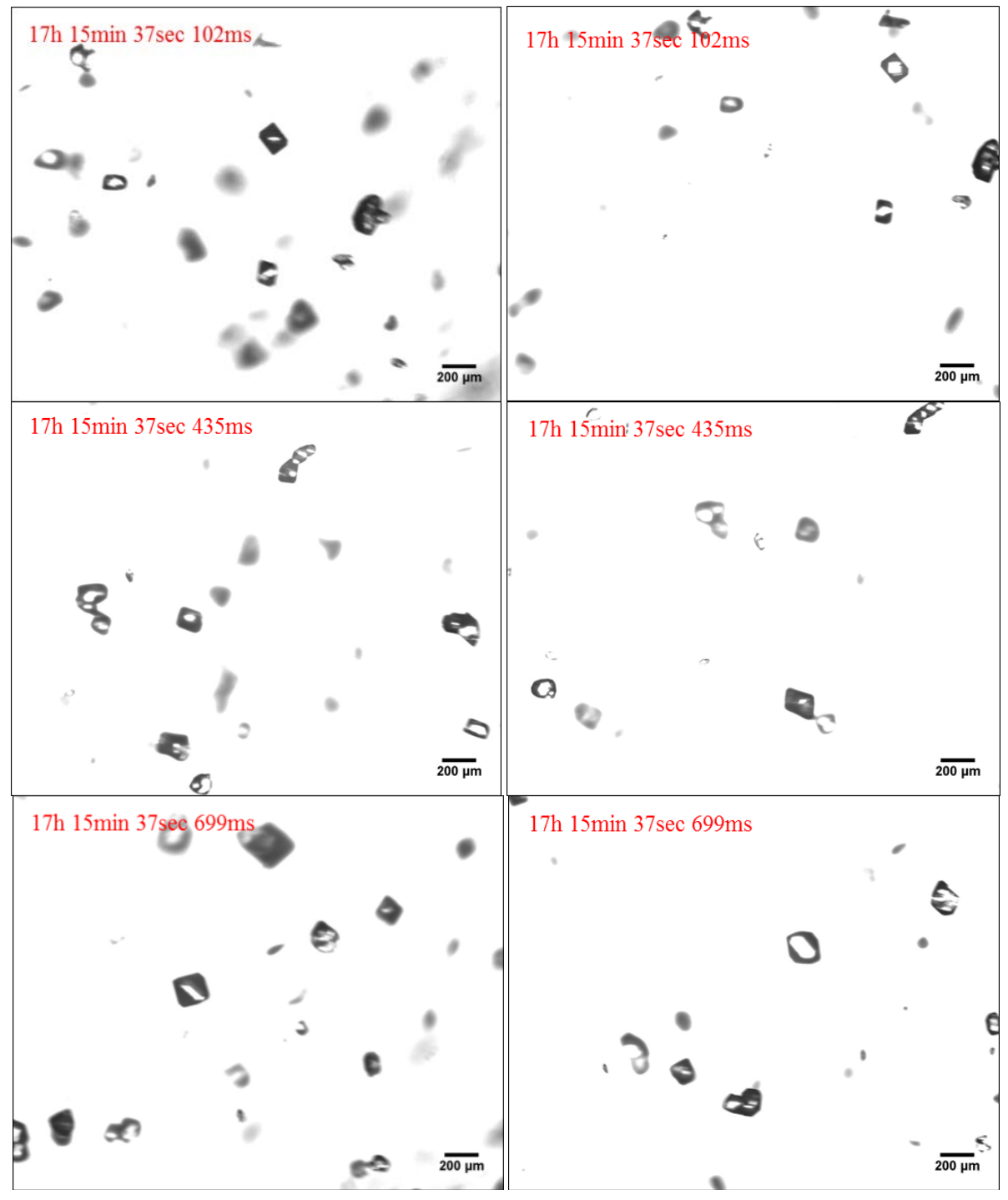




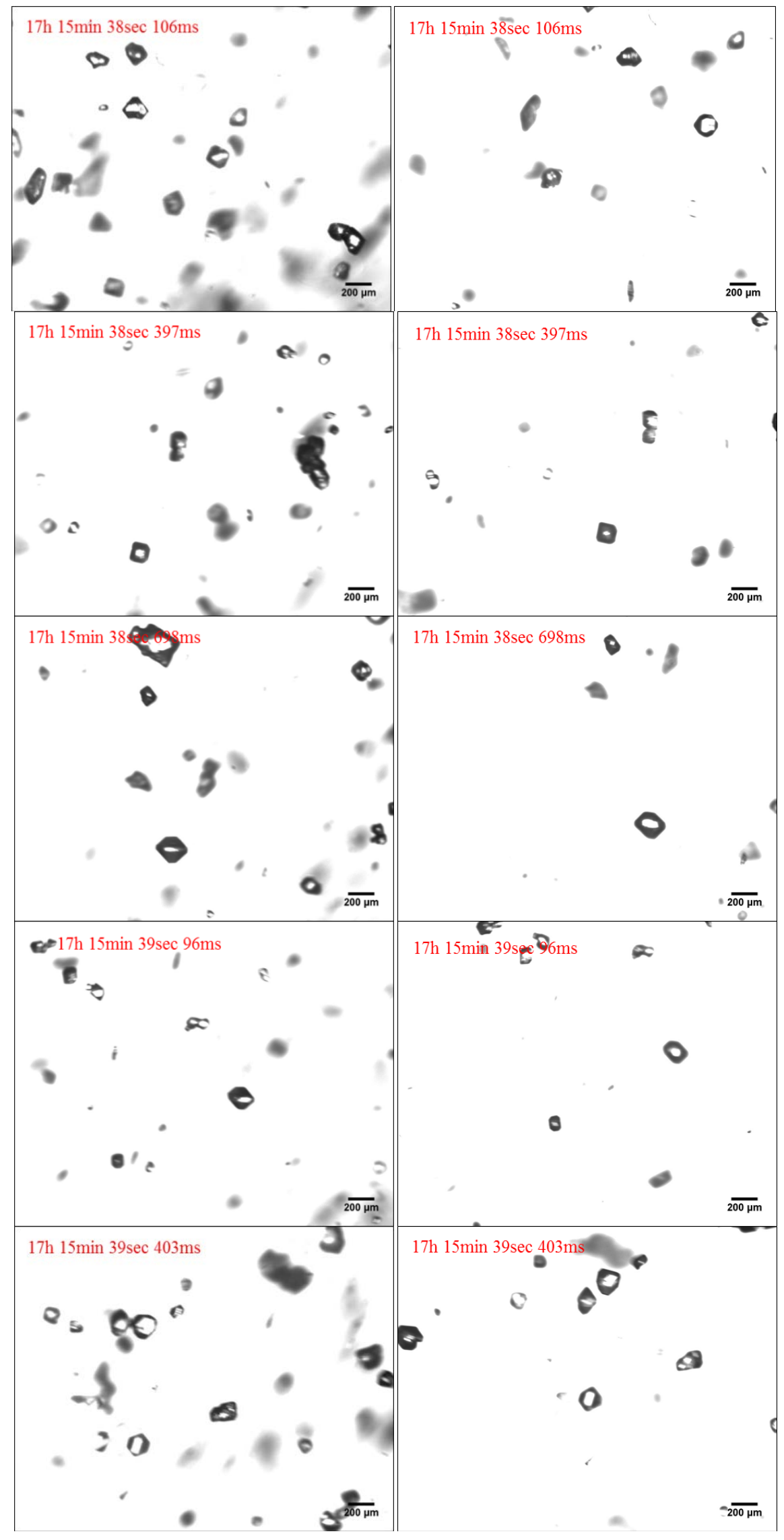




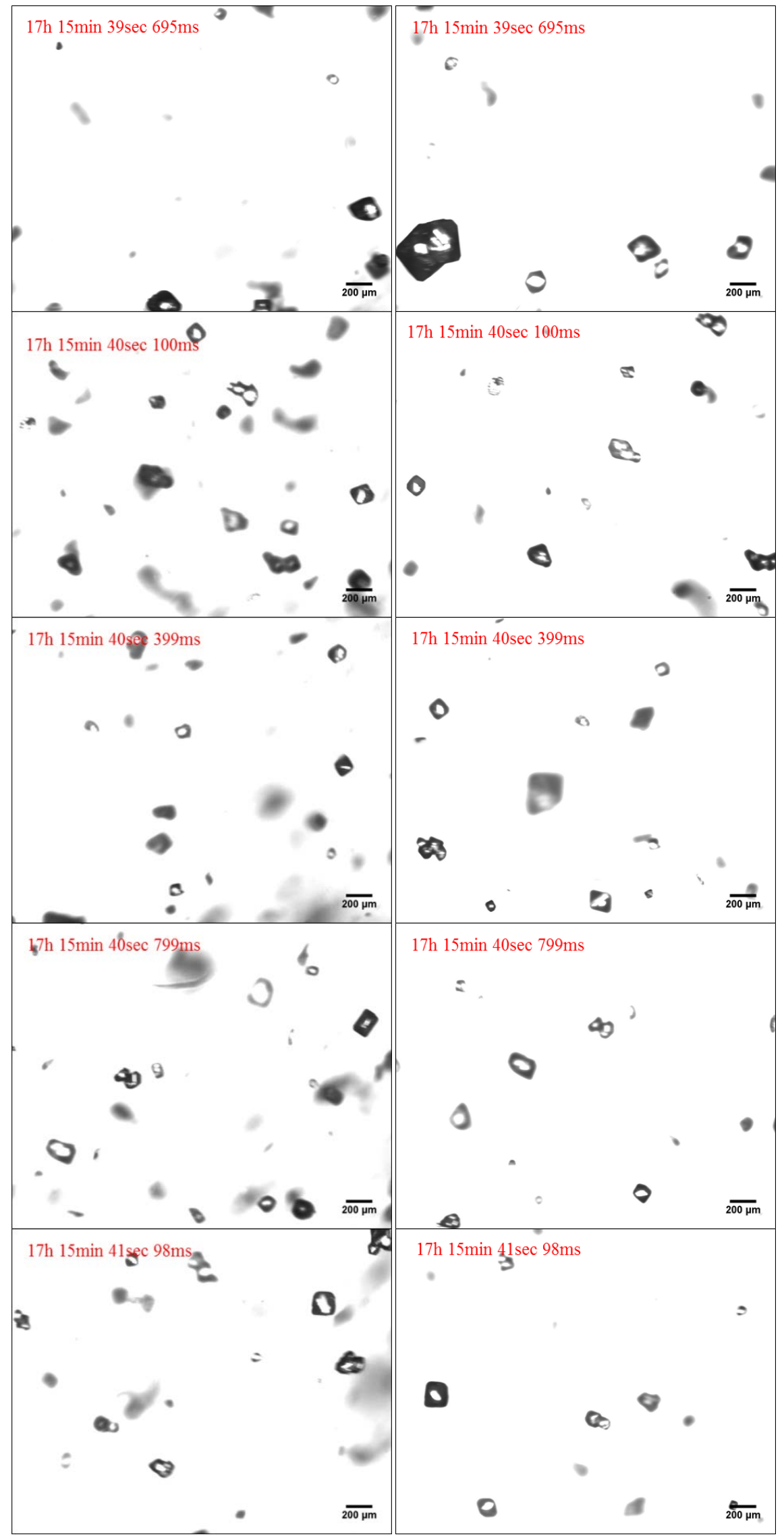




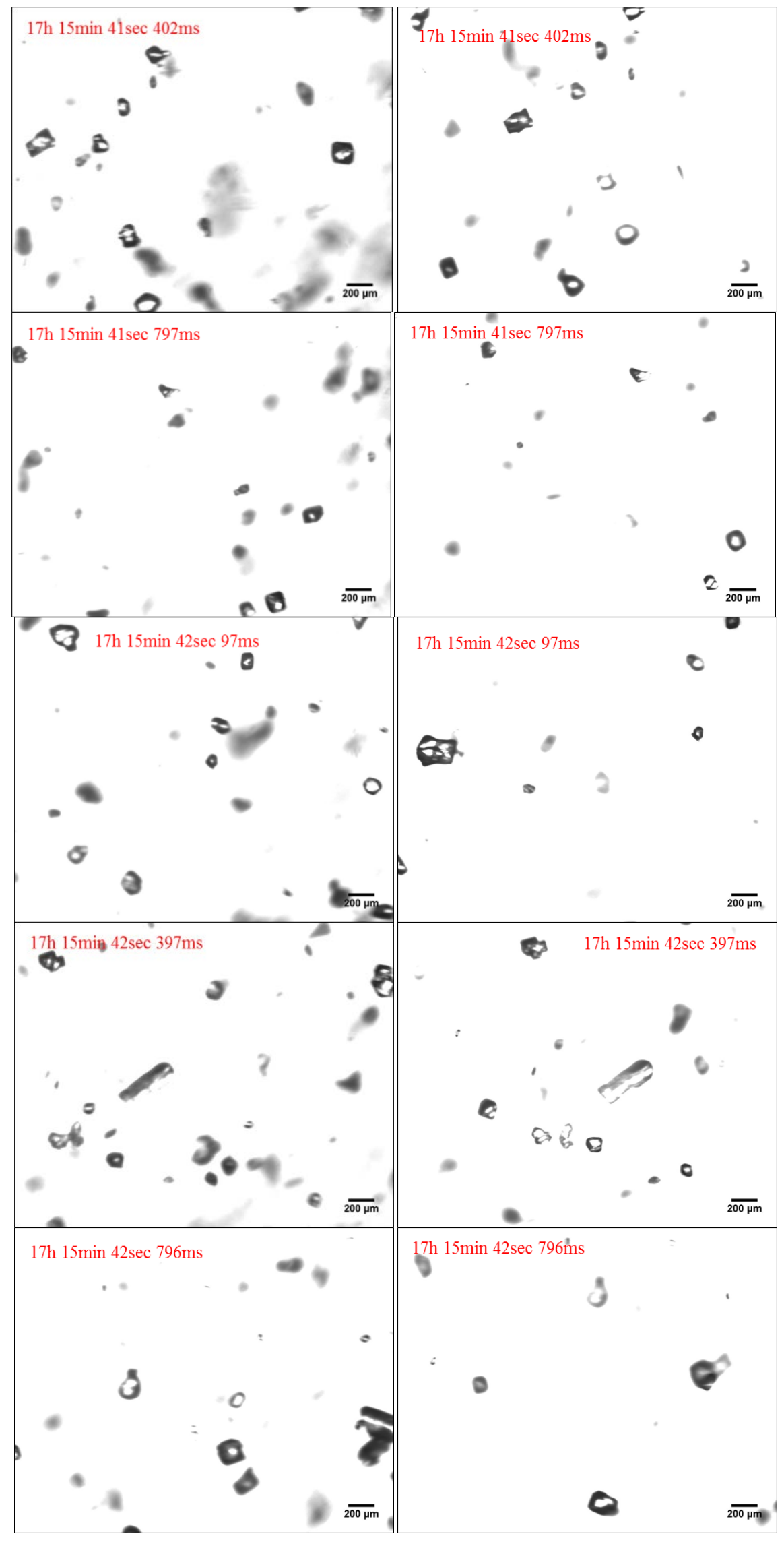




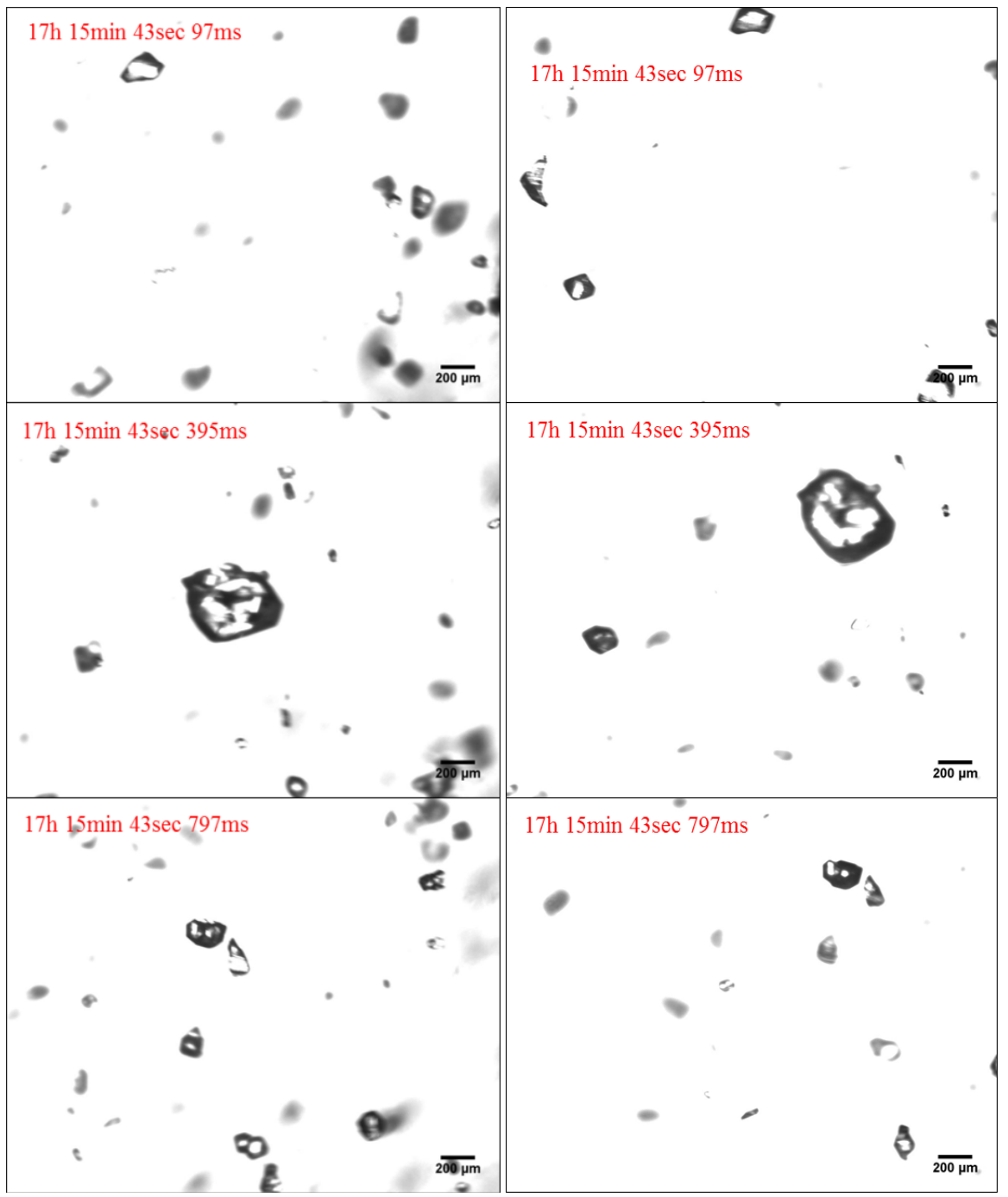

Figure S2. On-line images captured in $7 \mathrm{~s}$ (between $17 \mathrm{~h} 15 \mathrm{~min} 37 \mathrm{sec} 102 \mathrm{~ms}$ to $17 \mathrm{~h} 15$ $\min 43 \mathrm{sec} 797 \mathrm{~ms}$ ), the images from camera 1 (left) and camera 2 (right).

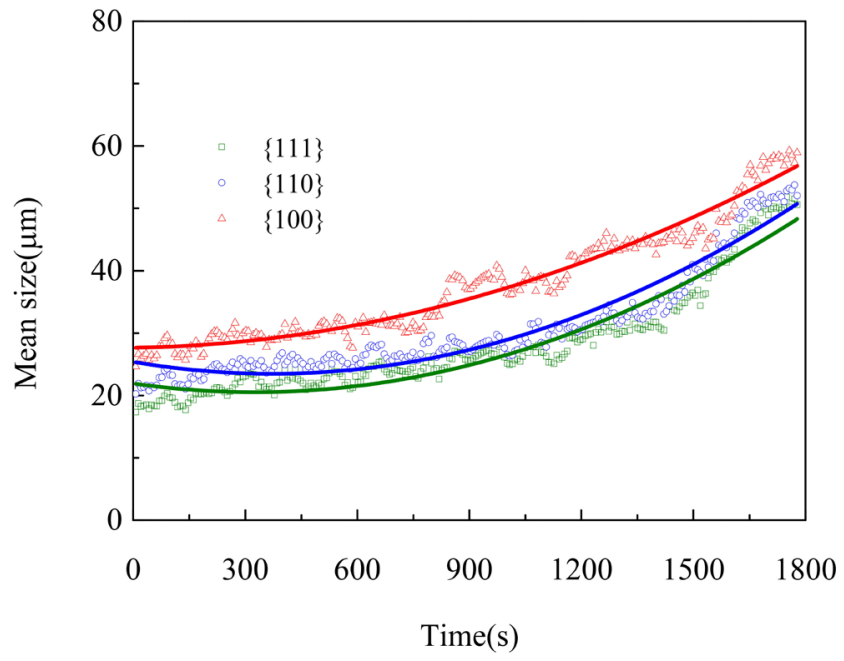

(a) 


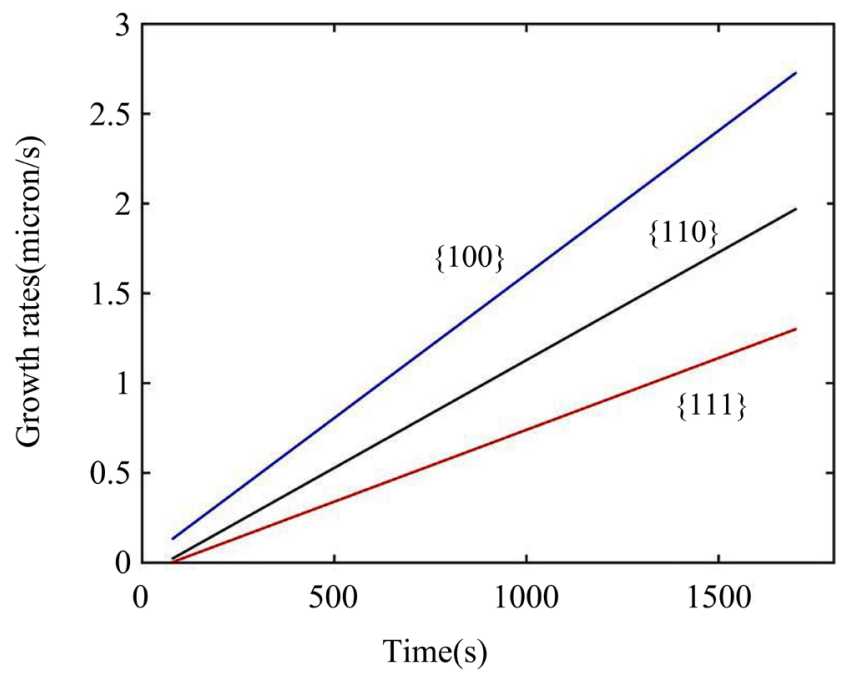

(b)

Figure S3. The averaged normal distances (a) covering 254 points and the corresponding growth rates (b) of three featured faces through 3D reconstruction. Each point represents the mean values in the previous $30 \mathrm{~s}$ (a point per four images). 